\author{
Universidade de São Paulo \\ Instituto de Física
}

\title{
Barreiras de Transporte em Plasmas e Mapas Simpléticos Não-Twist
}

\author{
Júlio César David da Fonseca \\ Orientador: Prof. Dr. Iberê Luiz Caldas
}

Dissertação de mestrado apresentada ao Instituto de Física para a obtenção do título de Mestre em Ciências.

Prof. Dr. Iberê Luiz Caldas - IFUSP (Orientador)

Prof. Dr. Ricardo Egydio de Carvalho - UNESP (Rio Claro)

Prof. Dr. Ricardo Luiz Viana - UFPR 


\section{FICHA CATALOGRÁFICA}

\section{Preparada pelo Serviço de Biblioteca e Informação}

do Instituto de Física da Universidade de São Paulo

Fonseca, Júlio César David da

Barreiras de transporte em plasmas e mapas simpléticos não-twist - . São Paulo, 2011

Dissertação de Mestrado - Universidade de São Paulo. Instituto de Física - Depto. de Física Aplicada

Orientador: Prof. Dr. Iberê Luiz Caldas

Área de Concentração: Física

Unitermos: 1. Física de Plasmas; 2. Fenômeno de Transporte; 3. Turbulência Eletrostática; 4. Caos 


\section{Agradecimentos}

Aos meus pais, avós e irmãos, pela coragem que sempre me inspiraram.

Ao Prof. Dr. Iberê Luiz Caldas, pela oportunidade de trabalhar em seu grupo de pesquisa e pelo constante apoio em todas as etapas do trabalho. Seu papel como professor e orientador é um exemplo a ser seguido.

Aos velhos e mais recentes amigos, que me acompanharam durante estes dois últimos anos: Marco Túlio, Luciano, Jeorgivan, Nancy, Dennis, Paula, Everton, Celso, Rafael, Lia, Danilo, Alberto, David e Gustavo. Todos vocês não apenas deram contribuições importantes para o trabalho, como também tornaram mais divertida a experiência de morar em São Paulo.

Finalmente, à CAPES e ao CNPq pelo suporte financeiro. 


\section{Resumo}

Consideramos um modelo hamiltoniano do movimento eletrostático de deriva para investigar o trasnporte caótico de partículas na borda de plasmas confinados em Tokamaks. Este modelo leva em conta a turbulência eletrostática de deriva, responsável pelo transporte anômalo. O modelo Hamiltoniano provê as equações de movimento, que são dependentes de uma função para o potencial elétrico. Esta função é caracterizada por um potencial de equilíbrio mais um termo correspondente às ondas de deriva. Assumimos três diferentes perfis radiais para o campo elétrico radial de equilíbrio: um linear e outros dois não-monotônicos com extremos "suaves". Para estes perfis, mostramos que o modelo pode ser reduzido a três mapas simpléticos bidimensionais e não integráveis: o mapa padrão, o mapa padrão não-twist e um mapa modelo não-twist introduzido neste trabalho. O mapa padrão não-twist e o mapa modelo violam a condição twist, fundamental para os teoremas KAM e de Birkhoff. Para estes mapas não-twist, estudaremos numericamente barreiras de transporte criadas próximas às curvas "shearless". Mostramos que, para o mapa modelo, a barreira de transporte é robusta, isto é, persiste em um amplo intervalo de variação de um de seus parâmetros. Dentro da região da barreira, descrevemos o nascimento de cadeias de ilhas com períodos par e ímpar devido à variação do parâmetro de controle. Analisamos estes dois cenários calculando os números de rotação dentro da barreira e identificando as bifurcações que criam as ilhas. Finalmente, conjecturamos que todas as ilhas dentro da região da barreira são criadas por estes dois cenários. Além disso, se o número de rotação da curva "shearless" atinge um número racional, as cadeias de ilhas são criadas de acordo com os cenários descritos. 


\section{Abstract}

We consider a hamiltonian model of the electrostatic drift motion to investigate chaotic particle transport in the Tokamak plasma edge. This model takes into account the electrostatic drift turbulence, which is responsible for the anomalous transport. The Hamiltonian model provides the basic equations of motion, which are dependent on the form of an electric potential function. This function is characterized by the equilibrium potential and the term corresponding to the drift waves. We assume three diferent radial profiles for the equilibrium radial electric field: one linear and the other two non-monotonic with a smooth extremum. For these profiles, we show that the model can be reduced to three symplectic maps: the standard map, the nontwist standard map, and a nontwist model map introduced in this work. The nontwist standard map and the model map violate the twist condition, a property of fundamental importance for the applicability of the KAM and Birkhoff theorems. For these nontwist maps, we study numerically the transport barriers created around their shearless curves. We show for the model map that the transport barrier is robust,i.e., remains for a wide range of one of its parameters. Inside the barrier region, we describe the birth of island chains with even or odd periods due to the control parameter variation. We analyse these two scenarios by calculating the winding numbers inside the barrier region and identifying the bifurcations that create the islands. Finally, we conjecture that all the island chains inside the barrier are created by these two scenarios. Moreover, if the winding number of the shearless curve reachs a rational number, the island chains are created according to the described scenarios. 


\section{Sumário}

1 Introdução 1

2 Transporte de Partículas em Tokamaks 5

2.1 Modelo para o Transporte de Partículas . . . . . . . . . . . . . 6

2.2 Mapa de Ondas de Deriva . . . . . . . . . . . . . . . . 7

2.3 Definições e Conceitos Básicos . . . . . . . . . . . . . . . . . . . . . 9

2.3.1 Órbitas Regulares e Caóticas . . . . . . . . . . . . . . . 9

2.3.2 Números de Rotação . . . . . . . . . . . . . . . . . . . . . . 11

2.3 .3 Mapa Simpléticos . . . . . . . . . . . . . . . . . . . . . . . 12

2.4 Mapas Twist . . . . . . . . . . . . . . . . . . . . . 13

2.4.1 Mapa Padrão . . . . . . . . . . . . . . . . . . 13

2.5 Mapas Não-Twist . . . . . . . . . . . . . . . . . . . . . . 15

2.5.1 Mapa Padrão Não-Twist . . . . . . . . . . . . . . . . . . . . . 16

2.5.2 Mapa Modelo . . . . . . . . . . . . . . . . 17

2.6 Conclusão . . . . . . . . . . . . . . . . . . . . . . . . . 18

3 Mapas de Ondas de Deriva $\quad 19$

3.1 Mapa Padrão . . . . . . . . . . . . . . . . . . . . . . . . . . . . 19

3.2 Mapa Padrão Não-Twist . . . . . . . . . . . . . . . . . . . . . 21

3.3 Mapa Modelo . . . . . . . . . . . . . . . . . . . . 25

3.4 Conclusão . . . . . . . . . . . . . . . . . . . . . . . . . . 28

4 Cenários de Formação de Órbitas Periódicas $\quad 29$

4.1 Órbitas de Período Par . . . . . . . . . . . . . . . . . . 30 
4.2 Órbitas de Período Ímpar . . . . . . . . . . . . . . . . . . . . . . . 32

4.3 Números de Rotação e Curvas "Shearless" . . . . . . . . . . . . . . . . . 33

4.3 .1 Cenário Par . . . . . . . . . . . . . . . . . . . 35

4.3 .2 Cenário Ímpar . . . . . . . . . . . . . . . . . . . . . . . . . 38

4.3 .3 Bifurcação da Curva Shearless . . . . . . . . . . . . . . . . . . . 41

4.4 Nascimento de Órbitas Periódicas . . . . . . . . . . . . . . . . . . . 42

4.5 Conclusão . . . . . . . . . . . . . . . . . . . . . . 51 


\section{Capítulo 1}

\section{Introdução}

Ao atingir altas temperaturas, a matéria se ioniza, transformando-se em um plasma, estado da matéria semelhante a um gás, formado por partículas carregadas e com elevada condutividade elétrica [1]. As pesquisas em física de plasmas constituem uma ativa área científica, motivada pela busca por fontes alternativas de energia, pela astrofísca e por novas tecnologias [2]. Este trabalho se insere no contexto da física de plasmas confinados magneticamente.

O objetivo da fusão por confinamento magnético é produzir energia a partir da reação nuclear entre os íons do plasma, submetido às condições de temperatura necessárias à fusão e confinado no reator com o uso de campos magnéticos. Um dos conceitos propostos para o confinamento magnético dos plasmas de fusão são os Tokamaks [3], onde as linhas de campo magnético assumem uma configuração toroidal. Entre os exemplos de Tokamaks, cabe citar o ITER [4], resultado de uma cooperação internacional cujo objetivo é demonstrar a viabilidade científica e tecnológica da fusão nuclear como fonte alternativa de energia.

O confinamento de plasmas em altas temperaturas por um tempo suficientemente longo, condição necessária para a fusão nuclear em tokamaks, requer a compreensão dos mecanismos que afetam o transporte de partículas. O transporte, chamado de "anômalo" por apresentar, nas observações experimentais, resultados diferentes em relação aos previstos pela teoria neoclássica, pode levar ao escape de partículas e perda de temperatura no plasma, além de danos às paredes internas do equipamento. Acredita-se que o transporte 
anômalo seja provocado pela turbulência. Portanto, o fenômeno da turbulência, típico em plasmas de fusão, deve ser controlado para que se tenha um eficiente confinamento do plasma [5]. A compreensão de como a turbulência causa o transporte anômalo, contudo, permanece como uma das questões fundamentais nas pesquisas em fusão magnética [6].

Barreira de transporte é uma região do plasma radialmente localizada em que se observa a redução ou mesmo eliminação dos níveis de transporte. O mesmo termo é empregado por [5] e [8] na caracterização do regime H-Mode ("high confinement regime"), que estaria associado ao surgimento de uma barreira de transporte. No regime H-Mode, ocorre um elevado gradiente de temperatura na borda do plasma e uma melhora das propriedades de confinamento. Este regime é o modo de operação a ser adotado pelo projeto ITER [9].

Embora as barreiras de transporte sejam importantes no controle do transporte anômalo e para a implementação do regime H-mode, pouco ainda se sabe sobre sua natureza e os mecanismos que levam à sua formação e estabilidade. Assim, é importante desenvolver estudos na área.

Nesta dissertação, estudamos um tipo de barreira de transporte. Nossos principais objetivos são: estudar em que condições esse tipo de barreira pode surgir e quais aspectos caracterizam sua estrutura interna.

O trabalho se inicia com um modelo físico Hamiltoniano, similar ao apresentado em [10] e que reproduz os efeitos da turbulência eletrostática sobre o transporte de partículas. São consideradas ondas (eletrostáticas) de deriva, que, segundo [11], são as principais responsáveis pelo transporte. Será visto que o sistema de equações diferenciais que caracterizam o modelo pode ser reduzido a um mapa simplético bidimensional e não integrável. Usaremos, ao longo de todo o trabalho, conceitos provenientes da teoria de mapas simpléticos não integráveis. Um mapa é chamado simplético quando o determinante da matriz jacobiana é igual a um.

Estes mapas bidimensionais são encontrados como mapas de Poincaré no estudo de sistemas dinâmicos Hamiltonianos tridimensionais. Umas das vantagens em usá-los é que aspectos qualitativos da dinâmica do sistema podem ser obtidos de um modo computacionalmente muito mais eficiente do que integrando numericamente as equações de Hamilton, 
pois a evolução do sistema é descrita de forma discreta no tempo.

Entres os mapas simpléticos bidimensionais, especial interesse será dado, neste trabalho, aos que violam a condição "twist" ou, como são geralmente chamados, mapas não-twist. Em um mapa que satisfaz a condição "twist", o perfil do número de rotação é monotônico. Mapas não-twist, além de serem encontrados em ampla variedade de modelos físicos, têm sido associados à formação de barreiras de transporte "robustas" no espaço de fase. Isso foi observado nos trabalhos [12-17], com aplicações envolvendo física de plasmas, e por [18], na área de dinâmica dos fluidos.

As equações do modelo dependem de como o perfil do campo elétrico radial varia com a coordenada radial. A influência da forma destes perfis sobre o transporte de partículas em Tokamaks foi analisada em [10]. Neste trabalho, serão considerados perfis que se diferenciam pela presença ou não de pontos sem "shear" (pontos de derivada nula). Com esses perfis obteremos três mapas simpléticos: o mapa padrão, o mapa padrão não-twist e o mapa modelo, sendo apenas os dois últimos do tipo não-"twist' e nos quais os perfis possuem pontos sem "shear". Nestes casos, observamos que ocorre a formação de uma barreira de transporte robusta. Atendemos, assim, à primeira parte dos nossos objetivos.

A segunda parte trata das propriedades que caracterizam a estrutura interna da barreira de um mapa não twist. A estrutura será analisada em termos das órbitas que a constituem. Isso será feito através do mapa modelo, proposto durante o trabalho de pesquisa para elaborar a dissertação e, também, discutido em [19]. Como é usual, obteremos numericamente órbitas do mapa para observar as alterações do mapa com os parâmetros de controle. Mostraremos que, como em outros mapas não-twists, esse mapa descreve a formação de barreira ao transporte. A seguir, investigaremos a quebra dessa barreira com a variação de um parâmetro de controle. Mostraremos que a quebra da barreira ocorre por uma sucessão de bifurcações que cria órbitas periódicas em cadeias de ilhas. Identificaremos dois cenários distintos de criação de cadeias de ilhas, um cenário com número par e outro com número impar de ilhas. Estes cenários apresentam um processo conhecido como "reconexão de separatrizes". Em [20], os autores analisam a ocorrência de processos de "reconexão" em um sistema hamiltoniano.

Apresentaremos a conjectura de que todas as ilhas (para a quebra da barreira) sejam 
criadas por um desses dois cenários. Além disso, calcularemos numericamente, a partir das órbitas periódicas observadas, o número de rotação das ilhas e os números de ressonância associados às mesmas. Assim, com a variação dos número de rotação dentro da barreira, devido a alterações no parâmetro de controle, identificamos as bifurcações das ilhas observadas.

Veremos que a barreira é uma camada de cadeias de ilhas e "curvas invariantes rotacionais". Outro importante aspecto é como essas cadeias e curvas se reconfiguram devido a variações em um dos parâmetros do mapa, exibindo os cenários de bifurcação, "reconexão de separatrizes" e a formação de "meanders", processos observados em outros mapas não-twist.

O capítulo 2 se inicia com a apresentação do modelo físico para o transporte de partículas. Em seguida, mostraremos que este modelo pode ser estudado através de um mapa simplético. Após uma breve seção que apresenta definições e conceitos básicos, mostra-se que, de acordo com o perfil escolhido para o campo elétrico radial, o mapa simplético pode ser escrito na forma do mapa padrão, do mapa padrão não-twist ou do mapa modelo. $\mathrm{Na}$ presença de pontos sem "shear" no perfil, viola-se, necessariamente, a condição "twist".

No capítulo 3, serão mostradas seções de Poincaré para estes mapas, descrevendo como ocorre a transição para o caos em cada um casos. Destaca-se, nos mapas não-twist, a existência de barreiras de transporte em amplas faixas de variação dos parâmetros de controle, mesmo quando o espaço de fase é caracterizado, predominantemente, por regiões caóticas.

O capítulo 4 mostra os resultados referente à estrutura da barreira de transporte no mapa modelo. Inicialmente, são apresentados dois cenários de bifurcaçao, com os quais se descrevem mudanças topológicas dentro da barreira devido a variações do parâmetro de controle. Estas mudanças se caracterizam, principalmente, pelo nascimento de órbitas periódicas. Verifica-se que os cenários estão diretamente relacionados com os números de rotação na área do espaço de fase referente à barreira.

No capítulo 5, são apresentadas as conclusões, além de idéias que possam dar continuidade a este trabalho. 


\section{Capítulo 2}

\section{Transporte de Partículas em}

\section{Tokamaks}

Este capítulo trata do contexto físico, das definições e métodos em que se baseiam os resultados dos capítulos posteriores. Inicialmente, apresenta-se um modelo para o transporte de partículas na borda de plasmas confinados em Tokamaks. As equações básicas do modelo, que descrevem o movimento do centro de guia da partícula, satisfazem o formalismo Hamiltoniano. A expressão para a Hamiltoniana depende de uma função para o potencial elétrico que leva em conta a presença de flutuações eletrostáticas na borda do plasma (ondas de deriva).

Em seguida, mostramos, na seção 2.2, que a parte da Hamiltoniana relacionada às flutuções é equivalente à soma de "termos impulsivos", que ocorrem em instantes múltiplos de um período fixo de tempo. Com isso, é possível obter, a partir das equações diferenciais que formam o modelo, o mapa de ondas de deriva.

A seção 2.3 abre espaço para definições e conceitos fundamentais na dinâmica de sistemas descritos por mapas: abordam-se os diferentes tipos de órbitas, a relação destas com o seu número de rotação e uma rápida discussão sobre mapas simpléticos.

A parte final do capítulo (seções 2.4 e 2.5) se dedica à apresentação das equações de mapas que representam casos particulares do mapa de ondas de deriva. O primeiro caso é o mapa padrão; os outros dois, o mapa padrão não-twist e o mapa modelo, ambos exemplos de mapas que violam a condição "twist". 


\subsection{Modelo para o Transporte de Partículas}

O modelo considera o fenômeno das ondas de deriva, principal responsável pelo transporte de partículas, energia e momento através das linhas de campo magnético [11]. As instabilidades de ondas de deriva resultam de gradientes de densidade e correspondem a ondas eletrostáticas que se propagam na direção poloidal. Para estudar as propriedades de transporte na borda do plasma, consideramos um modelo de ondas de deriva similar ao apresentado em [21]. De acordo com o modelo, o movimento das partículas, que cruzam as linhas de campo magnético, é governado pela deriva $\vec{E} \times \vec{B}$ dos centros de guia:

$$
\vec{v}_{C G}=\frac{\vec{E} \times \vec{B}}{B^{2}}
$$

Assumindo que o campo magnético toroidal seja $\vec{B}=B_{0} \hat{e}_{z}$, a velocidade de deriva dos centros de guia é dada por:

$$
\vec{v}_{C G}=-\frac{E_{x}}{B_{0}} \hat{e}_{y}+\frac{E_{y}}{B_{0}} \hat{e}_{x}
$$

Se $\vec{v}_{C G}=(\dot{x}(t), \dot{y}(t))$, as equações de movimento do centro de guia podem ser escritas como:

$$
\begin{aligned}
& \frac{d y}{d t}=\frac{1}{B_{o}} \frac{\partial \phi}{\partial x} \\
& \frac{d x}{d t}=-\frac{1}{B_{o}} \frac{\partial \phi}{\partial y}
\end{aligned}
$$

onde $x$ é a coordenada radial, $y$ corresponde ao ângulo poloidal e $\vec{E}=-\nabla \phi(x, y, t)$. Para um campo magnético uniforme, as equações 2.3 e 2.4 satisfazem a forma canônica de Hamilton [22] e podem ser reescritas como:

$$
\begin{aligned}
& \frac{d y}{d t}=\frac{\partial H(x, y, t)}{\partial x} \\
& \frac{d x}{d t}=-\frac{\partial H(x, y, t)}{\partial y}
\end{aligned}
$$

em que a função hamiltoniana é dada por:

$$
H(x, y, t)=\frac{\phi(x, y, t)}{B_{o}}
$$

A coordenada radial $x$ corresponde ao momento conjugado, e o ângulo poloidal $y$, à coordenada generalizada. Na equação 2.7, é necessária uma descrição para a função do 
potencial elétrico $\phi(x, y, t)$. Utilizaremos uma expressão similar à apresentada em [15], em que o potencial elétrico é formado por uma parte média radial, o potencial de equilíbrio $\phi_{o}(x)$, e outra flutuante, correspondente às ondas de deriva:

$$
\phi(x, y, t)=\phi_{o}(x)+\sum_{m=-\infty}^{+\infty} A \cos \left(k_{y} y-m \omega_{0} t\right)
$$

O potencial de equilíbrio provê a componente radial do campo elétrico, e a componente poloidal é dada pelas flutuações de deriva. Usaremos a hipótese de acordo com [15], em que, para um mesmo número de onda, existe um amplo espectro de frequências $m \omega_{0}$, onde $\omega_{0}$ corresponde à menor frequência do espectro com valor significativo de amplitude. Daí o modelo idealizado com infinitas ondas, tal como descrito pela pela equação 2.8. Outra simplificação é que assumiremos coerência de fase e amplitude igual e constante para todas as ondas.

\subsection{Mapa de Ondas de Deriva}

A partir das equações de movimento 2.3-2.4 e da função para o potencial elétrico 2.8, é possível mostrar que o modelo de transporte da seção 2.1 se reduz a um mapa. Será utilizado o mesmo procedimento tal como apresentado em [15] e [23]. A equação 2.8 pode ser escrita como:

$$
\phi(x, y, t)=\phi_{o}(x)+\sum_{m=-\infty}^{+\infty} A\left[\cos \left(k_{y} y\right) \cos \left(m \omega_{0} t\right)+\operatorname{sen}\left(k_{y} y\right) \operatorname{sen}\left(m \omega_{0} t\right)\right]
$$

O segundo termo do somatório pode ser eliminado, uma vez que:

$$
\sum_{m=-\infty}^{+\infty} \operatorname{sen}\left(m \omega_{0} t\right)=0
$$

Aplicando a série de Fourier da função delta de Dirac, com período $T=2 \pi / \omega_{0}$, pode-se verificar que:

$$
\sum_{m=-\infty}^{+\infty} \cos \left(m \omega_{0} t\right)=2 \pi \sum_{m=-\infty}^{+\infty} \delta\left(\omega_{0} t-2 \pi m\right)
$$

Usando as identidades 2.10 e 2.11 em 2.9, chega-se à seguinte equação para o potencial elétrico:

$$
\phi(x, y, t)=\phi_{o}(x)+2 \pi A \cos \left(k_{y} y\right) \sum_{m=-\infty}^{+\infty} \delta\left(\omega_{0} t-2 \pi m\right)
$$


Sejam $x_{n}$ e $y_{n}$ as coordenadas da posição da partícula em um instante inferior e infinitesimalmente próximo de $\tau_{n}$, isto é:

$$
\begin{aligned}
& x_{n}=x\left(\tau_{n}-\varepsilon\right) \\
& y_{n}=y\left(\tau_{n}-\varepsilon\right),
\end{aligned}
$$

onde $\tau_{n}=n T$, para $n \in \mathbb{N}$, e $\varepsilon \rightarrow 0$. Integrando a equação de movimento 2.4 de $\tau_{n}-\varepsilon$ até $\tau_{n+1}-\varepsilon$ :

$$
x_{n+1}-x_{n}=-\frac{1}{B_{o}} \int_{\tau_{n}-\varepsilon}^{\tau_{n+1}-\varepsilon} \frac{\partial \phi}{\partial y} d t,
$$

E substituindo $\phi$ pela função obtida em 2.12, temos:

$$
x_{n+1}=x_{n}+\frac{2 \pi k_{y} A}{B_{o}} \operatorname{sen}\left(k_{y} y\right) I_{n}
$$

onde o termo $I_{n}$ é dado por:

$$
I_{n}=\frac{1}{\omega_{0}} \sum_{m=-\infty}^{+\infty} \int_{\tau_{n}-\varepsilon}^{\tau_{n+1}-\varepsilon} \delta(t-T m) d t
$$

Pela definição da função delta de Dirac, a integral em 2.17 é igual a 0 para todos os valores de $T m$ fora do intervalo $\left(\tau_{n}-\varepsilon, \tau_{n+1}-\varepsilon\right)$. O produto $T m$ pertence ao intervalo apenas quando $m=n$, e, neste caso, a integral é igual a 1 . Assim,

$$
I_{n}=\frac{1}{\omega_{0}}
$$

Integrando, novamente, de $\tau_{n}-\varepsilon$ até $\tau_{n+1}-\varepsilon 2.3$ e substituindo $\phi$ por 2.12 , temos:

$$
y_{n+1}=y_{n}+\frac{1}{B_{o}} \int_{\tau_{n}-\varepsilon}^{\tau_{n+1}-\varepsilon} \frac{d \phi_{0}}{d x}[x(t)] d t,
$$

O valor da coodernada radial $x$ "salta" a cada instante de tempo múltiplo do período $T$, pois o potencial $\phi$ em 2.12 é formado pelos termos impulsivos $\delta(t-T m)$. No entanto, para instantes entre dois múltiplos consecutivos de $T, \tau_{m}$ e $\tau_{m+1}$, os termos impulsivos são nulos, $\phi=\phi_{0}$ e, então, $x$ é constante, uma vez que, de acordo com $2.4, \dot{x}=\partial_{y}\left[\phi_{0}(x)\right]=0$. Portanto,

$$
x(t)= \begin{cases}x_{n}, & \tau_{n-1}<t<\tau_{n} \\ x_{n+1}, & \tau_{n}<t<\tau_{n+1} .\end{cases}
$$


Reescrevendo 2.19 em dois intevalos de integração e aplicando 2.20, vemos que:

$$
\begin{aligned}
y_{n+1} & =y_{n}+\frac{1}{B_{o}}\left[\left.\int_{\tau_{n}-\varepsilon}^{\tau_{n}} d t \frac{d \phi_{o}}{d x}\right|_{x=x_{n}}+\left.\int_{\tau_{n}}^{\tau_{n+1}-\varepsilon} d t \frac{d \phi_{o}}{d x}\right|_{x=x_{n+1}}\right] \\
& =y_{n}+\frac{1}{B_{o}}\left[\left.\varepsilon \frac{d \phi_{o}}{d x}\right|_{x=x_{n}}+\left.T \frac{d \phi_{o}}{d x}\right|_{x=x_{n+1}}\right] .
\end{aligned}
$$

Substituindo 2.18 em 2.16 e eliminando o termo que depende de $\varepsilon$ em 2.21, temos:

$$
\begin{aligned}
& x_{n+1}=x_{n}+\frac{2 \pi A k_{y}}{\omega_{0} B_{o}} \sin \left(k_{y} y_{n}\right) \\
& y_{n+1}=y_{n}+\left.\frac{2 \pi}{\omega_{0} B_{o}} \frac{d \phi_{o}}{d x}\right|_{x=x_{n+1}}
\end{aligned}
$$

Aspectos qualitativos relacionados ao modelo da seção 2.1 podem ser descritos através das equações 2.22 e 2.23, que chamaremos aqui de mapa de ondas de deriva ou, simplesmente, $M_{T}$.

\subsection{Definições e Conceitos Básicos}

A evolução de um sistema dinâmico pode ser descrita por um conjunto de equações diferenciais ou, de forma discreta no tempo, através de um mapa. Mapas são transformações $\left\{M: E \longmapsto E \mid z^{\prime}=M(z)\right\}$, onde $z^{\prime}$ e $z$ são pontos do espaço de fase $E$. Neste trabalho, consideram-se apenas os mapas que estejam definidos em um domínio bi-dimensional e cilíndrico: $E=\{(x, y) \in \mathbb{R} \times \mathbb{T}\}$, onde $\mathbb{T}$ é o espaço topológico correspondente ao círculo (toro de dimensão igual a 1). De modo mais simples, $E$ corresponde a um cilindro. À coordenada $y$, faremos referência com o nome coordenada angular, cujos valores, por convenção, ficam restritos ao intervalo $[0,1)$.

\subsection{1 Órbitas Regulares e Caóticas}

Uma órbita corresponde à sequência de pontos $\left\{\ldots, z_{n}, z_{n+1}, \ldots\right\}$, tal que $z_{n+1}=M\left(z_{n}\right)$. Uma órbita regular é aquela que apresenta um padrão bem definido, através do qual se pode prever, com relativa precisão e olhando apenas para seu aspecto gráfico, por que pontos do espaço de fase a órbita passa. Um órbita não-regular recebe o nome de órbita caótica. Estas órbitas percorrem áreas muito mais amplas do espaço de fase de modo 
aparentemente "aleatório": não é possível inferir um padrão na sequência de pontos da órbita, qualquer que seja o número de iterações do mapa. Além disso, órbitas caóticas caracterizam-se por grande sensibilidade às condições iniciais: pequenas mudanças no estado inicial podem resultar em estados futuros cuja distância varia exponencialmente com o número de iterações. A sensibilidade às condições iniciais é medida através do expoente de lyapunov, que pode determinar se uma órbita é regular ou caótica [24].

Órbitas regulares podem ser periódicas ou quase-periódicas. Uma órbita é periódica se retorna ao mesmo ponto após um número finito de iterações. Mais precisamente, se $z_{0}=M^{q}\left(z_{0}\right)$, para uma condição inicial $z_{0}$ e um número $q$ mínimo de iterações, diz-se que a órbita $O=\left\{z_{0}, \ldots, z_{q-1}\right\}=\left\{z_{n}\right\}_{n=0}^{q-1}$ é periódica. O período de $O$ é definido pelo número $q$. Se $q=1, z_{0}$ é chamado de ponto fixo de $M$. Os pontos $z_{0}, \ldots, z_{q-1}$ são pontos fixos de $M^{q}$.

Um órbita regular é chamada quase-periódica quando passa por pontos arbitrariamente próximos em relação ao ponto inicial, mas sem retornar, exatemente, a este ponto. Uma órbita quase-periódica apresenta uma grande densidade de pontos dentro de um conjunto uni-dimensional, de modo que, para um número suficientemente grande de iterações, estas órbitas se parecem com "curvas contínuas" e fechadas no espaço de fase.

Quando a projeção da curva sobre o eixo y passa por todo o intervalo [0,1), isto é, quando contorna todo o cilindro antes de se fechar, ela recebe o nome de círculo invariante rotacional (CIR). Uma curva $C$ é invariante se $C=M(C)$. O nome "círculo rotacional" significa que a curva é topologicamente equivalente ao círculo $x=0$. A importância dos CIR's, como veremos no capítulo 3, reside no fato de que, em mapas bi-dimensionais, estas curvas formam barreiras de transporte. No decorrer deste trabalho, órbitas quaseperiódicas que pertencem a um CIR, serão chamadas, por razões de simplicidade, de curvas invariantes.

Um órbita quase-periódica pode estar associada a um círculo que não é rotacional. Neste caso, a a curva se fecha sem contornar o cilindro. A região delimitada pela curva é usualmente chamada de ilha ou ressonância. No capítulos 3, são apresentados exemplos gráficos de ilhas e curvas invariantes. 


\subsubsection{Números de Rotação}

No capítulo 4, estudam-se processos de bifurcação analisando os números de rotação de órbitas que ocorrem no mapa modelo. Para mapas cujo espaço de fase é representado pela superfície de um cilindro, como é caso de todos os mapas discutidos neste trabalho, define-se o número de rotação como:

$$
\omega\left(z_{0}\right)=\lim _{n \rightarrow \infty} \frac{\left(\hat{y}_{n}-\hat{y}_{n-1}\right)+\left(\hat{y}_{n-1}-\hat{y}_{n-2}\right)+\ldots+\left(\hat{y}_{1}-\hat{y}_{0}\right)}{n}=\lim _{n \rightarrow \infty} \frac{\sum_{i=1}^{n} \Delta \hat{y}_{i}}{n} .
$$

onde $z_{0}=\left(x_{0}, y_{0}\right)$ é uma condição inicial, e $\hat{y}_{n}$ corresponde à coordenada angular $y$ na $n$-ésima iteração sem considerar o uso do operador mod no mapa, ou seja:

$$
\left(\hat{x}_{n}, \hat{y}_{n}\right)=\left(x_{n}, y_{n}+m\right), \quad m \in \mathbb{Z}
$$

Assim, $\hat{y}_{n}$ satisfaz a relação $\hat{y}_{n}(\bmod 1)=y_{n}$ e não fica limitado ao intervalo $[0,1)$. Somando e subtraindo termos $\hat{y}_{k}$, onde $k \in 1,2, \ldots, n-1$, a equação 2.24 pode ser ser reescrita de um modo computacionalmente mais simples:

$$
\omega=\lim _{n \rightarrow \infty} \frac{\hat{y}_{n}}{n}
$$

De acordo com 2.24, número de rotação $\omega\left(z_{0}\right)$ corresponde à média dos deslocamentos, na direção angular $y$, feitos pela órbita com condição inicial em $z_{0}$. Recorrendo, novamente, ao modelo de ondas de deriva, vê-se que o número de rotação $\omega$ de uma órbita descrita pelo mapa 2.22-2.23 é proporcional à velocidade poloidal média $\bar{v}_{y}$ do centro de guia da partícula:

$$
\omega=T \bar{v}_{y}
$$

onde $T$, como foi visto na seção 2.2, é o intervalo de tempo associado a cada iteração do mapa. A equação 2.27 vincula, assim, o conceito de velocidade média e número de rotação.

O tipo da órbita também está relacionado com o seu número de rotação:

- O limite 2.26 não existe para órbitas caóticas; o número de rotação, portanto, está definido apenas para órbitas regulares. 
- Uma órbitas periódica $\left\{\left(x_{n}, y_{n}\right)\right\}_{n=0}^{q-1}$ satisfaz a propriedade:

$$
M^{q}\left(x_{n}, \hat{y}_{n}\right)=\left(x_{n}, \hat{y}_{n}+p\right) \quad \forall i=0, \ldots, q-1 .
$$

Antes de retornar ao ponto inicial, a órbita, cujo período é dado por $q$, percorre p "voltas" ao redor do cilindro. O limite 2.26, neste caso, é um número racional $p / q$. Por isso, o nome órbita racional também é usado para designar uma órbitas periódica.

- O número de rotação de uma curva invariante é irracional. Por esta razão, órbitas quase-periódicas que representam curvas invariantes são também chamadas de órbitas irracionais.

\subsubsection{Mapa Simpléticos}

Outra definição relacionada a mapas é a de matriz jacobiana. A matriz jacobiana $J$ para um mapa $M$ é dada por:

$$
J_{i j}=\frac{\partial[M(z)]_{i}}{\partial z_{j}} .
$$

Os índices $i$ e $j$, quando usados em $z$ e $M(z)$, designam, respectivamente, as $i$-ésima e $j$-ésima coordenadas desses pontos. Se o determinante de $J$ for igual à unidade:

$$
\operatorname{det}(J)=1
$$

$M$ é chamado de mapa simplético. Usando a definição 2.29 , a matriz jacobiana $J_{T}$ para o mapa de ondas de deriva $\left(M_{T}\right)$ é dada por:

$$
J_{T}=\left(\begin{array}{cc}
\frac{\partial x_{n+1}}{\partial x_{n}} & \frac{\partial x_{n+1}}{\partial y_{n}} \\
\frac{\partial y_{n+1}}{\partial x_{n}} & \frac{\partial y_{n+1}}{\partial y_{n}}
\end{array}\right)
$$

Substituindo as equações 2.22 e 2.23 em 2.31, verifica-se que $M_{T}$ satisfaz 2.30 e que, portanto, é simplético.

Como foi visto nas seções 2.1 e $2.2, M_{T}$ foi obtido a partir de um sistema hamiltoniano bi-dimensoninal, onde $\left(x_{n+1}, y_{n+1}\right)=M_{T}\left(x_{n}, y_{n}\right)$ é a posição da partícula após o intervalo de tempo $T$ e com condição inicial em $\left(x_{n}, y_{n}\right)$. Mapas que derivam de sistemas dinâmicos hamiltonianos, de modo que, se $z_{0}$ é um estado inicial e $M\left(z_{0}\right)$ corresponde ao estado do 
sistema após um certo intervalo de tempo, são mapas simpléticos [25]. Tal fato confere um papel importante aos mapas simpléticos no estudo da dinâmica caótica de sistemas hamiltonianos, especialmente quando aplicados em experimentos numéricos [26].

\subsection{Mapas Twist}

Seja $\left(x_{n+1}, y_{n+1}\right)=S\left(x_{n}, y_{n}\right)$ um mapa simplético. Consideremos, ainda, que o espaço de fase esteja definido na superfície de um cilindro e que $y$ seja a coordenada angular. $S$ recebe o nome de mapa twist se existe um numero $\kappa$ tal que:

$$
\left|\frac{\partial y_{n+1}}{\partial x_{n}}\right| \geq \kappa>0
$$

A partir de pontos mais altos ao longo de uma reta vertical (valores maiores de $x_{n}$, mantendo $y_{n}$ fixo), uma órbita realiza "saltos" cada vez maiores na direção horizontal (valores maiores de $y_{n+1}$ ).

Suponha que o mapa simplético $S$ possa ser escrito na forma das equações:

$$
\begin{aligned}
& x_{n+1}=x_{n}+g\left(y_{n}\right) \\
& y_{n+1}=y_{n}+f\left(x_{n+1}\right) .
\end{aligned}
$$

Neste caso, a condição 2.32 pode ser reescrita através da função $f$ :

$$
\begin{aligned}
\left|\frac{\partial y_{n+1}}{\partial x_{n}}\right| & =\left|\frac{\partial f\left(x_{n+1}\right)}{\partial x_{n+1}} \frac{\partial x_{n+1}}{\partial x_{n}}\right| \\
& =\left|\frac{d f\left(x_{n+1}\right)}{d x_{n+1}}\right| \geq \kappa>0 .
\end{aligned}
$$

A função $f$, que chamaremos de função twist, corresponde a variação da coodernada angular $y$ a cada iteração do mapa. Da propriedade 2.35, resulta que $f$ é monotonicamente crescente ou decrescente em relação a $x_{n+1}$.

\subsubsection{Mapa Padrão}

Não é possível obter uma descrição numérica para o modelo da seção 2.1 sem que se defina $\phi_{0}$ na equação 2.23. Para completar o modelo, suponha que, na borda do plasma 
tenhamos o seguinte potencial de equilíbrio:

$$
\phi_{0}(x)=\frac{\gamma x^{2}}{2}
$$

para $\gamma>0$. Uma vez que $\vec{E}=-\nabla \phi(x, y, t)$, o campo elétrico radial na borda do plasma será dado por:

$$
E_{x}=-\frac{d \phi_{o}}{d x}=-\gamma x
$$

Considere as seguintes definições:

$$
\begin{aligned}
x^{\prime} & =\frac{\gamma k_{y}}{\omega_{0} B_{0}} x \\
y^{\prime} & =\frac{k_{y} y}{2 \pi} \\
a & =2 \pi A \gamma\left(\frac{k_{y}}{\omega_{0} B_{0}}\right)^{2} .
\end{aligned}
$$

O mapa de ondas de deriva (eqs. 2.22 e 2.23) pode, então, ser escrito na forma do mapa padrão:

$$
\begin{aligned}
& x_{n+1}^{\prime}=x_{n}^{\prime}+a \operatorname{sen}\left(2 \pi y_{n}^{\prime}\right) \\
& y_{n+1}^{\prime}=y_{n}^{\prime}+x_{n+1}^{\prime}, \quad \bmod 1
\end{aligned}
$$

O mapa padrão mantém a mesma estrutura das equações 2.33 e 2.33. A função twist é dada por $f(x)=x$ e, de acordo 2.37, está relacionada com o perfil do campo elétrico radial pela equação:

$$
f(x)=-\frac{E_{x}(x)}{\gamma}
$$

O perfil de $E_{x}$ é descrito pelo gráfico da figura 2.1. A condição 2.35 é satisfeita, pois:

$$
\frac{d f(x)}{d x}=1,
$$

o que faz do mapa padrão, portanto, um exemplo de mapas do tipo twist. O mapa padrão, também conhecido pelo nome de mapa de Chirikov-Taylor é um dos mais importantes mapas na teoria de caos conservativo, e, através dele, é possível mostrar propriedades da transição para o caos em sistemas conservativos clássicos [27]. 


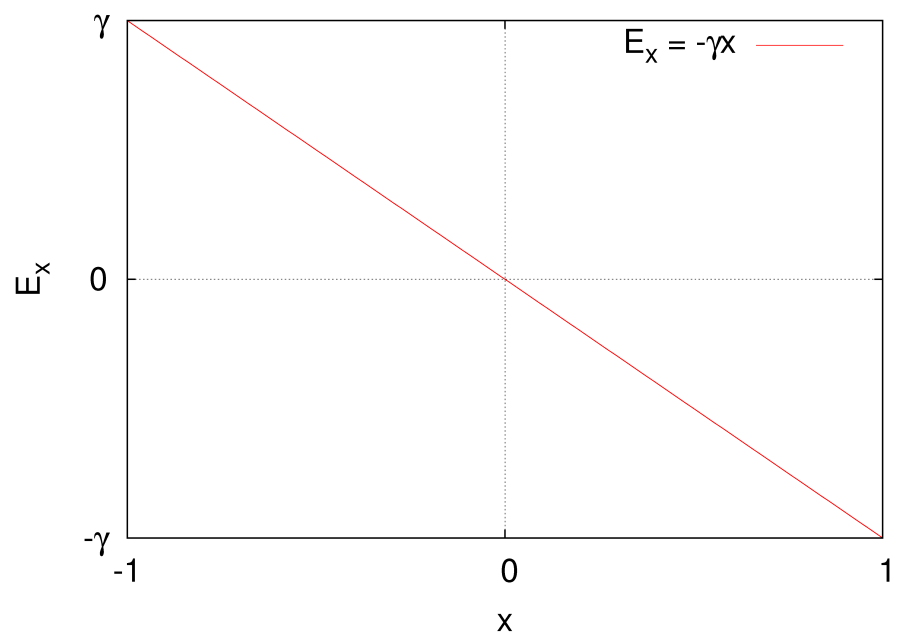

Figura 2.1: Campo elétrico radial na borda do plasma: $E_{x}=-\gamma x$. Para este perfil, o mapa de ondas de deriva se reduz ao mapa padrão.

\subsection{Mapas Não-Twist}

Se a condição twist, definida por 2.32, for violada em uma região qualquer do espaço de fase, o mapa é chamado de não-twist. Resultados importantes ligados a mapas simpléticos, como é o caso do teorema KAM, baseiam-se na validade da condição twist [28,29]. Portanto, se um modelo físico se reduz a um mapa não-twist, estes resultados não podem mais ser utilizados. Daí sua relevância não apenas do ponto de vista das aplicações físicas como também no desenvolvimento da teoria de sistemas dinâmicos. Apesar disso, existem poucos trabalhos teóricos que explicam a rica fenomenologia numérica exibida pelos mapas não-twist [30].

Os chamados "meanders" são órbitas especiais, encontradas nos mapas não-twist. Esses "meanders" são curvas invariantes que se deformam de tal modo que não podem ser descritas como gráficos de funções da coodernada angular [29,30]. De acordo com [31-33], estas curvas ocorrem apenas em mapas não-twist, uma vez que qualquer curva invariante, em um mapa twist, dever representar o gráfico de uma função $x(y)$.

Nas seções 2.5.1 e 2.5.2, consideram-se exemplos de mapas que violam a condição 2.32: o mapa padrão não-twist e o mapa modelo. Exemplos de "meanders" são ilustrados para estes mapas nos capítulos 3 e 4 . Assim como o mapa padrão, ambos derivam do mapa de ondas de deriva. No entanto, assume-se que o campo elétrico radial tenha um perfil 


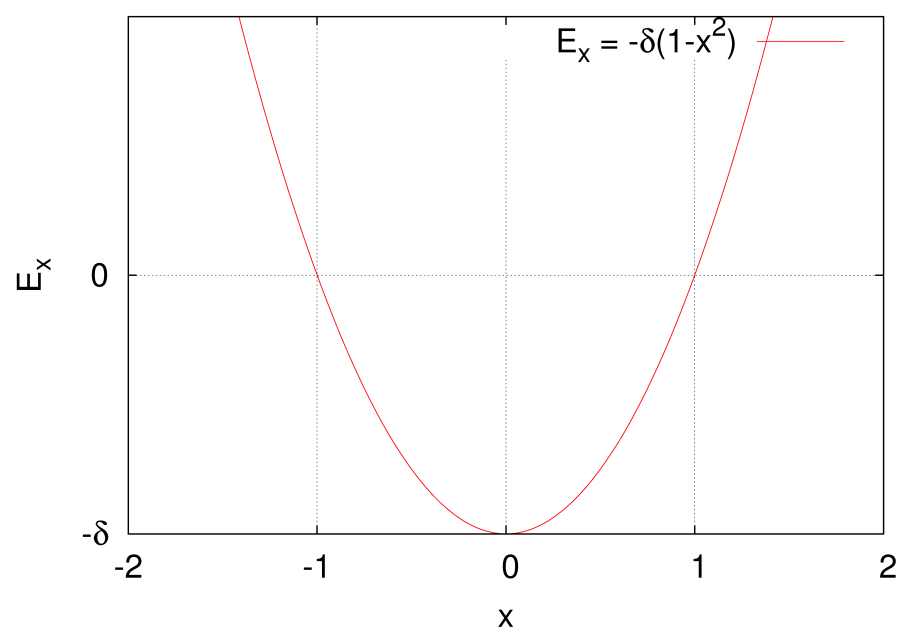

Figura 2.2: Para o perfil do campo elétrico radial definido pela função $E_{x}=-\delta\left(1-x^{2}\right)$, o mapa de ondas de deriva pode ser escrito na forma do mapa padrão não-twist.

não-monotônico, o que pode ser provocado por uma instabilidade na borda do plasma ou criado por técnicas de controle (ver, por exemplo, "biasing schemes" em [34]).

\subsubsection{Mapa Padrão Não-Twist}

Supondo que o potencial de equilíbrio possa ser escrito como:

$$
\phi_{0}(x)=\delta\left(x-\frac{x^{3}}{3}\right)
$$

o campo elétrico radial será caracterizado pela função:

$$
E_{x}=-\frac{d \phi_{o}}{d x}=-\delta\left(1-x^{2}\right),
$$

onde $\delta$ é uma constante real e positiva. O gráfico de $E_{x}$ é mostrado na figura 2.2. Com o uso das definições:

$$
\begin{aligned}
x^{\prime} & =x & y^{\prime} & =\frac{k_{y} y}{2 \pi} \\
a & =-\frac{2 \pi A k_{y}}{\omega_{0} B_{0}} & b & =\frac{k_{y} \delta}{\omega_{0} B_{0}},
\end{aligned}
$$

é possível verificar que o mapa de ondas de deriva pode ser escrito na forma do mapa padrão não-twist, estudado em diversos trabalhos (ver, por exemplo, [35] e [36]):

$$
\begin{aligned}
& x_{n+1}^{\prime}=x_{n}^{\prime}-a \operatorname{sen}\left(2 \pi y_{n}^{\prime}\right) \\
& y_{n+1}^{\prime}=y_{n}^{\prime}+b\left(1-x_{n+1}^{\prime 2}\right), \quad \bmod 1
\end{aligned}
$$


De acordo com 2.23 e 2.50, a função twist, assim como no mapa padrão, é proporcional ao campo elétrico radial:

$$
f(x)=-\frac{k_{y}}{\omega_{0} B_{0}} E_{x}(x)=b\left(1-x^{2}\right) .
$$

Existe um valor de $x(x=0)$ em que a condição 2.32 não é valida, o que explica o termo "não-twist" para o mapa das equações 2.49 e 2.50 .

\subsubsection{Mapa Modelo}

Outro exemplo de mapa não-twist é o que se apresenta, neste trabalho, com o nome de mapa modelo. Assumiremos que o potencial de equilíbrio seja dado pela função:

$$
\phi_{0}= \begin{cases}-\frac{\alpha x^{4}}{4}, & x<0, \\ \frac{\alpha x^{4}}{4}, & x \geq 0\end{cases}
$$

onde $\alpha>0$. Teremos, portanto, um campo elétrico radial não-monotônico da forma:

$$
E_{x}=-\frac{d \phi_{o}}{d x}=-\alpha|x|^{3}
$$

Este perfil é descrito pelo gráfico da figura 2.3. Aplicando, novamente, as definições 2.47 e usando os parâmetros:

$$
a=\frac{2 \pi A k_{y}}{\omega_{0} B_{0}} \quad b=\frac{\alpha k_{y}}{\omega_{0} B_{0}},
$$

as equações do mapa modelo serão dadas por:

$$
\begin{aligned}
& x_{n+1}^{\prime}=x_{n}^{\prime}+a \operatorname{sen}\left(2 \pi y_{n}^{\prime}\right) \\
& y_{n+1}^{\prime}=y_{n}^{\prime}+b\left|x_{n+1}^{\prime}\right|^{3}, \quad \bmod 1
\end{aligned}
$$

A função twist, resultante do campo elétrico radial definido em 2.53:

$$
f(x)=-\frac{k_{y}}{\omega_{0} B_{0}} E_{x}(x)=b|x|^{3} .
$$

Derivando 2.57 em relação a $x$, obtém-se:

$$
\frac{d f(x)}{d x}= \begin{cases}-3 b x^{2}, & x<0 \\ +3 b x^{2}, & x \geq 0\end{cases}
$$




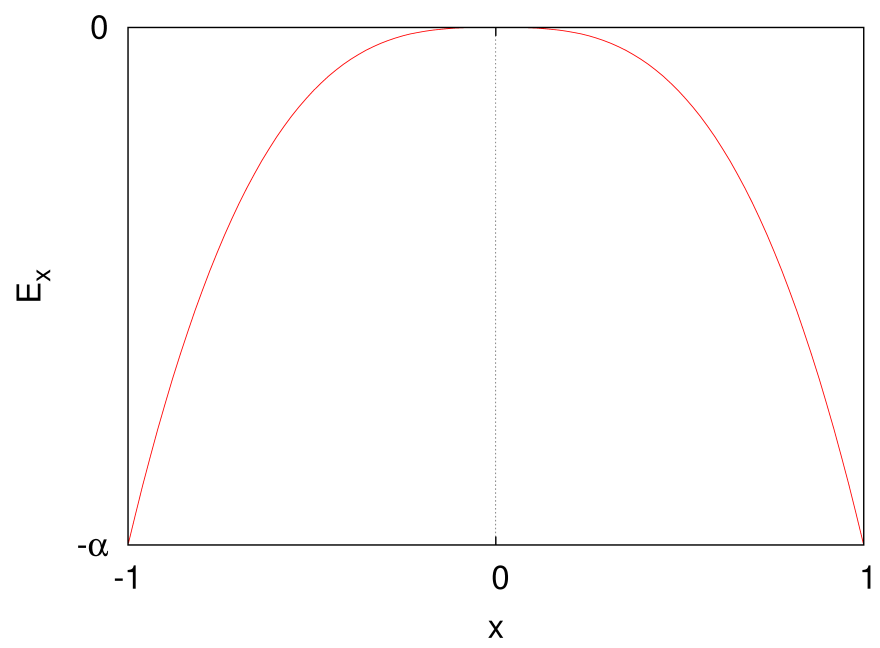

Figura 2.3: Para o perfil do campo elétrico radial dado por $E_{x}=-\alpha|x|^{3}$, o mapa de ondas de deriva resulta em outro tipo de mapa não-twist: o mapa modelo.

O mapa modelo é não-twist, uma vez que, de acordo com 2.58, a condição 2.32 não é válida para $x=0$. Todos os resultados apresentados no capítulo 4 se baseiam neste mapa, que representa outra possível descrição numérica do modelo de ondas de deriva.

\subsection{Conclusão}

A partir de um modelo para o transporte de partículas em plasmas confinados em Tokamakas, obtivemos um mapa simplético, o mapa de ondas de deriva. A hamiltoniana do modelo é proporcional à função do potencial elétrico, caracterizada por um termo, o potencial de equilíbrio, mais um outro que traduz os efeitos das ondas de deriva.

Instabilidades espontâneas na borda do plasma ou a aplicação de métodos que controlam o perfil campo elétrico radial, permitem-nos assumir funções para o potencial de equilíbrio. Usando estas funções, três casos particulares do mapa de ondas de deriva foram apresentados: o mapa padrão, o mapa padrão não-twist e o mapa modelo. O perfil do campo elétrico radial, em cada um casos, determina se o mapa viola ou não a condição twist. 


\section{Capítulo 3}

\section{Mapas de Ondas de Deriva}

Neste capítulo, analisam-se resultados numéricos para os três mapas apresentados no capítulo 2: o mapa padrão, o mapa padrão não-twist e o mapa modelo. Para cada um desses mapas, apenas um parâmetro de controle, a, é alterado. O objetivo é comparar esses três mapas quanto às mudanças que ocorrem no espaço de fase devido a variações desse parâmetro de controle. As sequências de figuras ilustram a rota para o caos para cada um dos mapas: inicia-se com um um valor pequeno do parâmetro $a$, e aumenta-se o parâmetro de controle até que a região caótica seja predominante. Especial atenção é dada aos casos em que se observa a formação de barreiras que restringem o transporte a regiões específicas do espaço de fase.

\subsection{Mapa Padrão}

Exemplos numéricos para o mapa padrão são mostrados nas figuras 3.1(a)-(d). O caso com um valor baixo para o parâmetro de controle $(a \approx 0)$ se encontra na fig.3.1(a), em que apenas curvas invariantes são observadas. Como vimos no capítulo 2, a função twist para o mapa padrão é dada por $f(x)=x$, o que equivale a dizer que o número de rotação varia de modo aproximadamente linear com a coordenada $x$. Na figura 3.1(b), um grande número de curvas invariantes ainda sobrevivem, mas apresentam um grau de deformação maior em relação ao caso anterior. Cadeias de ilhas são visíveis, além de duas pequenas regiões caóticas sobre as separatrizes das cadeias principais, que correspondem às ilhas de 


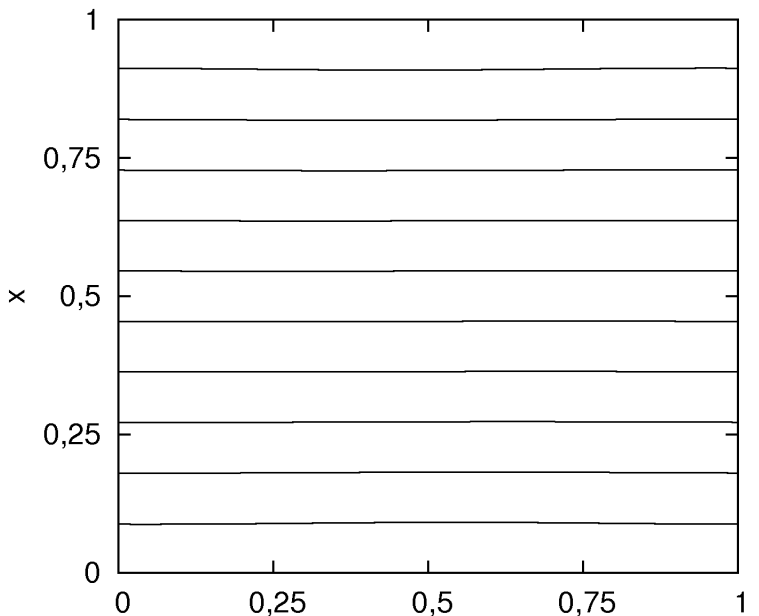

(a)

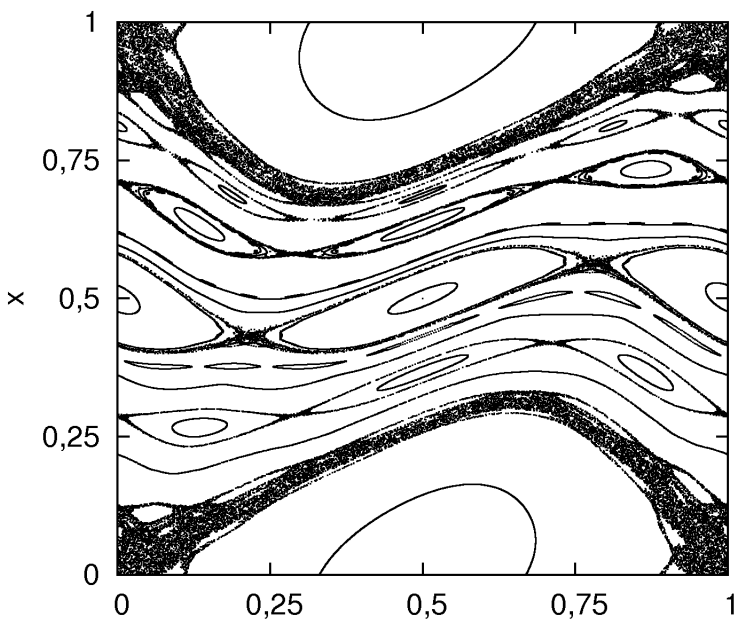

(c)

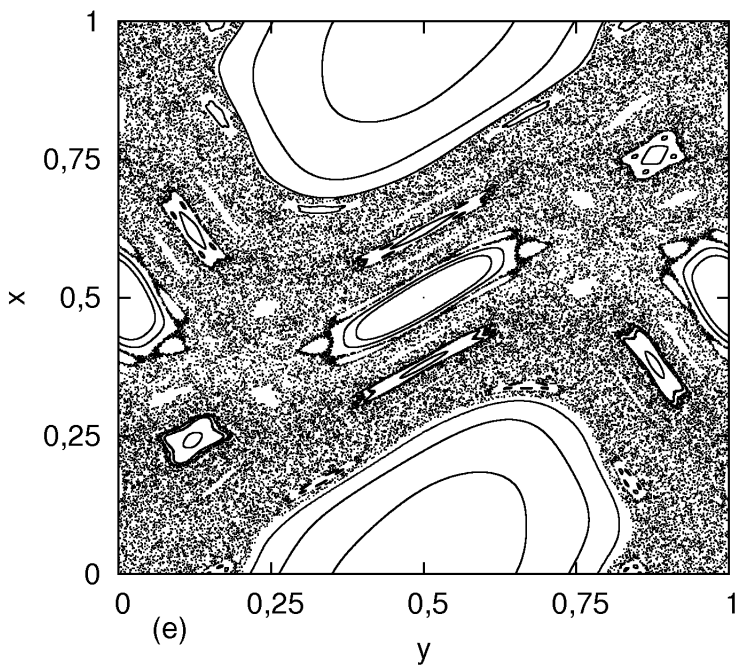

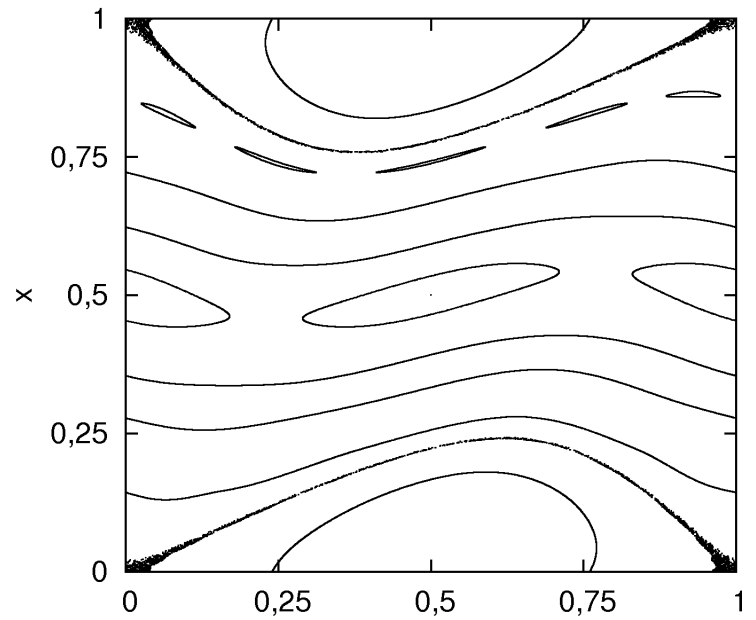

(b)

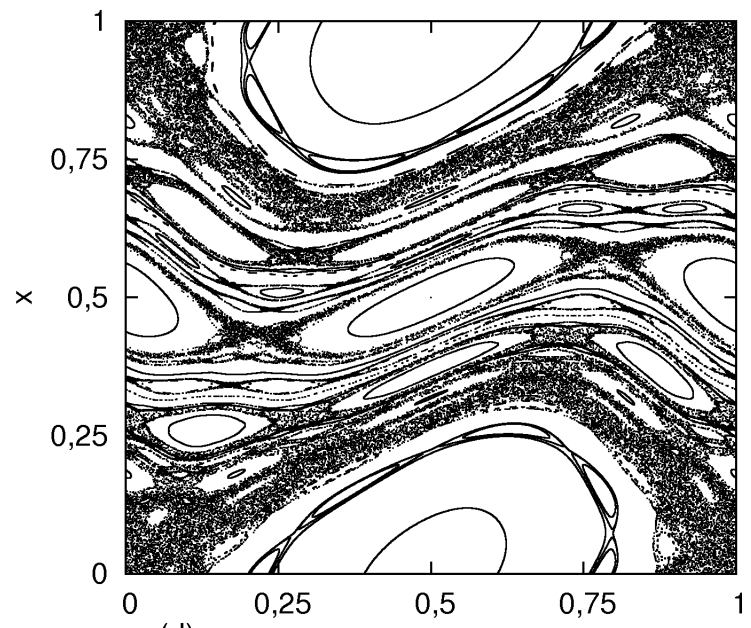

(d)

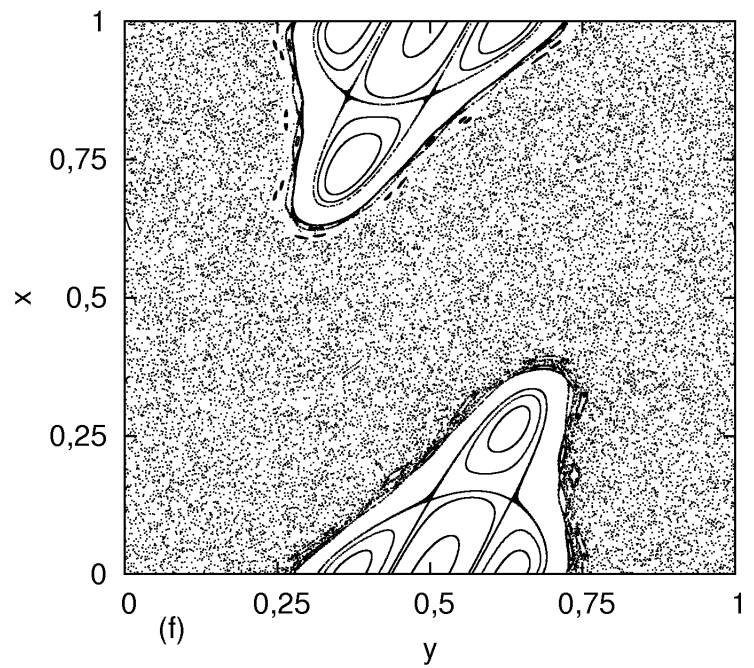

Figura 3.1: Mapa padrão para $b=0.1$. Parâmetro de controle: (a) $a=1 \times 10^{-4}$; (b) $a=0,087$; (c) $a=0,135$; (d) $a=0,153$; (e) $a=0,198$; (f) $a=0,359$. 
maior tamanho.

O aumento do parâmetro de controle leva a uma expansão significativa das duas regiões caóticas, como podemos ver na fig.3.1(c). No entanto, as duas regiões permanecem separadas por uma outra formada predominantemente por cadeias de ilhas e curvas invariantes. Essa região intermediária se apresenta como uma barreira de transporte, impedindo que órbitas da região caótica inferior alcancem a região caótica superior.

A região intermediária, porém, não sobrevive a um elevado aumento do parâmetro de controle (ver fig.3.1(d)): ela não apenas regride "de fora para dentro" com o avanço das duas principais regiões caóticas, como também sofre uma erosão "de dentro para fora" devido ao crescimento das regiões caóticas menores, também localizadas sobre separatrizes de cadeias de ilhas. Como se pode observar na figura 3.1(e), as curvas invariantes desaparecem, e as cadeias se rompem, deixando as ilhas isoladas em meio ao caos. Na figura 3.1(f), a maior parte das ilhas já não é visível, e o caos domina quase todo o espaço de fase.

\subsection{Mapa Padrão Não-Twist}

Resultados para o mapa padrão não-twist são apresentados na sequência de figuras 3.2(a)-(d). Como já se espera, valores muitos pequenos do parâmetro de controle resultam em um mapa caracterizado pelas curvas invariantes paralelas à direção do eixo y (ver fig.3.2(a)). A função twist possui perfil não-monotônico, uma vez que $f(x)=b\left(1-x^{2}\right)$. O número de rotação, que equivale à função twist para este caso, é uma parábola com concavidade voltada para baixo. A curva invariante localizada em $x=0$ possui o máximo número de rotação. Com o aumento do parâmetro de controle, as regiões superior e inferior, próximas a $x=+1$ e $x=-1$, são tomadas por órbitas caóticas, como se pode verificar na fig.3.2(b). Na região intermediária, próxima a $x=0$, uma barreira de curvas invariantes impede o transporte entre as regiões superior e inferior. Ainda na mesma região, observa-se um par de cadeias de ilhas, cujos pontos elípticos são aproximadamente indicados pelos pontos em azul e verde. Entre as duas cadeias, existe uma fina região de curvas invariantes, e uma delas está indicada em vermelho. 


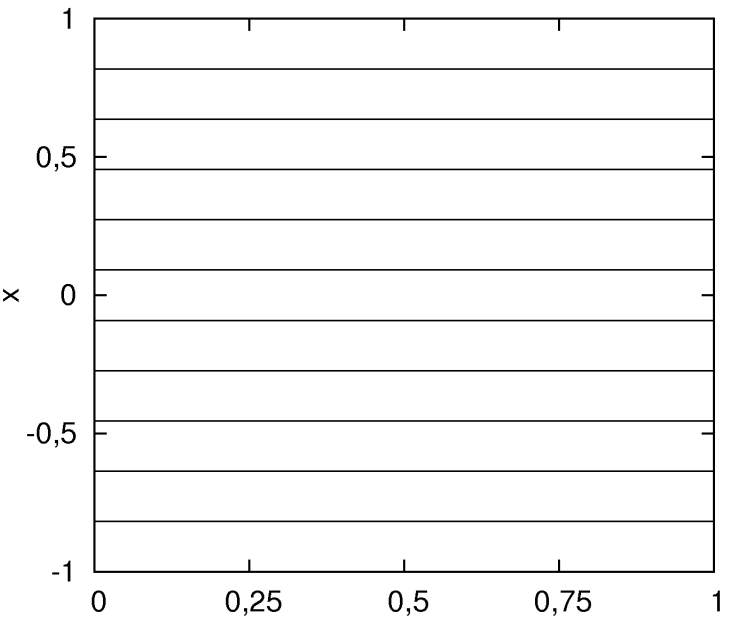

(a)

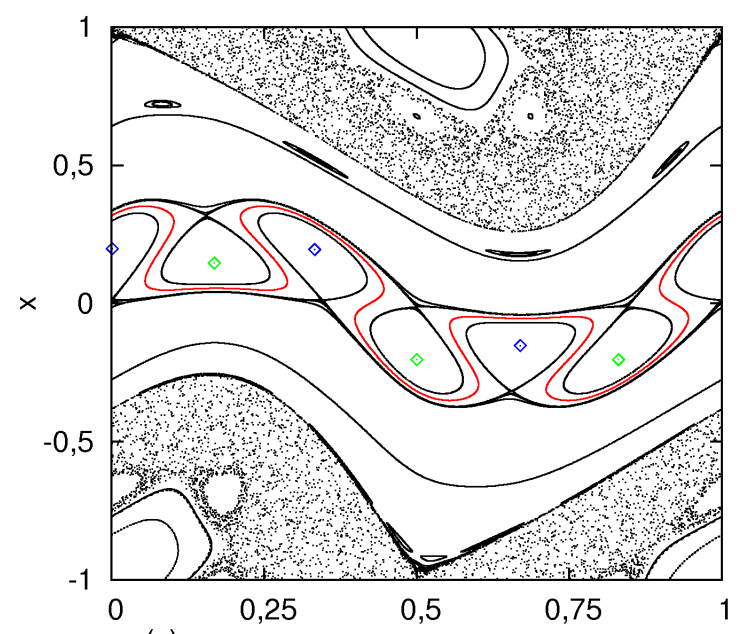

(c)

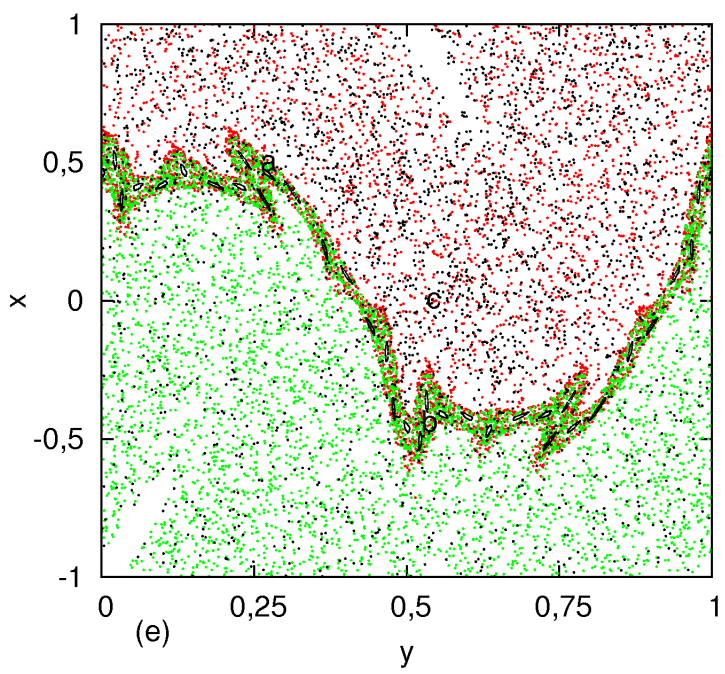

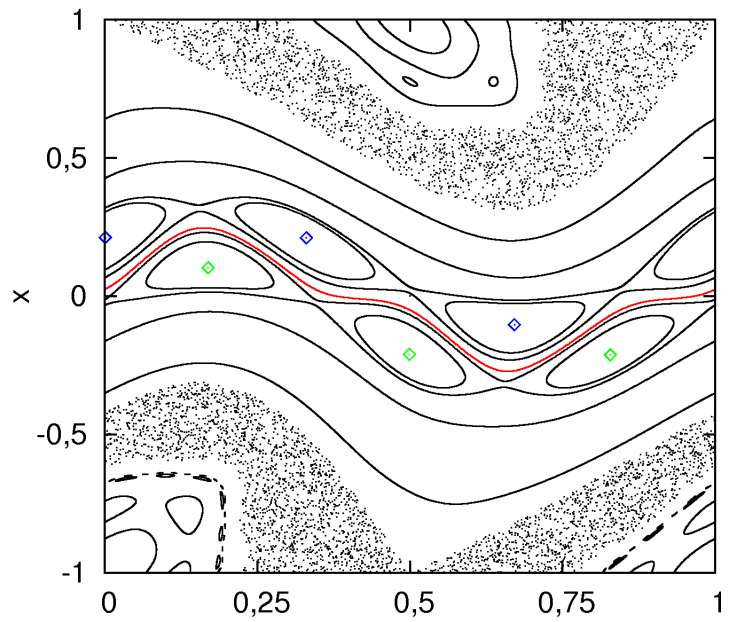

(b)
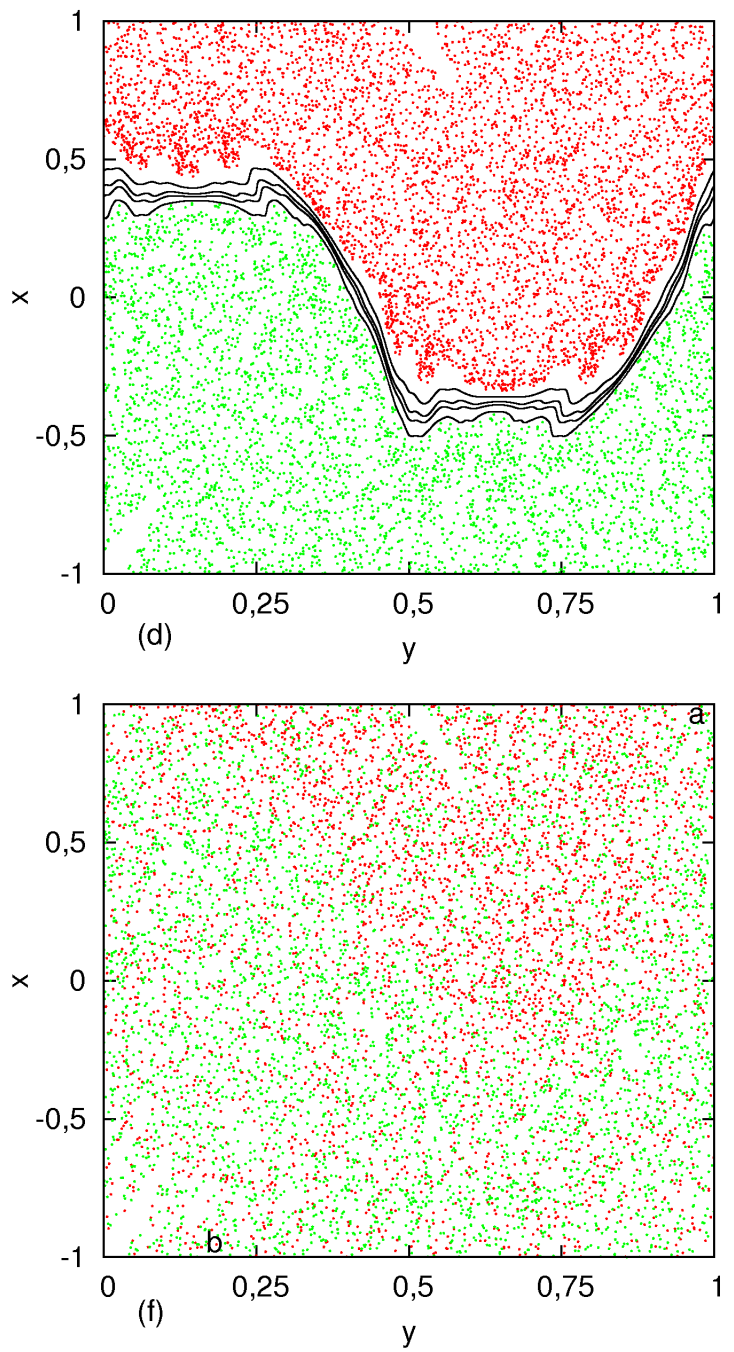

Figura 3.2: Mapa padrão não-twist para $b=0,354$. Parâmetro de controle: (a) $a=1 \times 10^{-6}$; (b) $a=0,358$; (c) $a=0,4$; (d) $a=0,8$; (e) $a=0,879$; (f) $a=0,925$. 
A 3.2(c) mostra como a curva invariante e o par de cadeias se modificam com o aumento do parâmetro de controle. A primeira se deforma, contornando os pontos elípticos da ilhas e assumindo a forma de um meander. Como já discutimos no capítulo 1, os meanders não podem ser caracterizados como gráficos de funções da coordenada $y$ : mais de um ponto da curva em vermelho podem estar associados a um único valor de $y$. Em relação ao par de cadeias, a mudança mostrada através das figs. 3.2(b) e 3.2(c) recebe o nome de reconexão de separatrizes.

Antes da reconexão (fig. 3.2(b)), as ilhas com pontos azuis se encontram na região superior à curva em vermelho, e as com pontos em verde localizam-se na região inferior. Após a reconexão (fig. 3.2(c)), as duas cadeias trocam de posição. Esse processo ocorre repetidas vezes para diferentes valores do parâmetro de controle e para cadeias com diferentes números de ilhas.

Na figura 3.2(d), órbitas caóticas dominam, praticamente, todo o espaço de fase. A exceção é uma fina camada de curvas invariantes que separam completamente duas órbitas caóticas, uma na região superior (com pontos vermelhos) e outra na inferior (com pontos verdes). Ao contrário do mapa padrão, em que uma pequena variação no parâmetro de controle provoca um rápido crescimento de pequenas regiões caóticas em todo o espaço fase (comparemos as figuras 3.1(c),(d) e (e) para observar esse efeito), a barreira de transporte no mapa padrão não-twist permanece bem definida para um intervalo significativo do parâmetro de controle.

Já evidente nas figs.3.2(b) e (c) com suas curvas invariantes e processos de reconexão, a barreira tem a espessura diminuída progressivamente até que ocorre sua quebra. No caso anterior da 3.2(d), uma órbita cuja condição inicial se encontre em uma das duas regiões caóticas ficara sempre confinada na região a que pertence a condição inicial em razão da presença da barreira de transporte. No caso da figura 3.2(e), a barreira foi quebrada, pois a órbita caótica $c$, que parte da condição inicial localizada sobre a letra de mesmo nome e cujos pontos estão todos em preto, ocupa toda a área do espaço de fase indicada na figura.

Embora a órbita $c$ não fique restrita a uma área específica, observa-se que existe mais pontos dessa órbita em uma região do que em outra. Além disso, a fronteira que dificulta o transporte entre as duas regiões é análoga à area antes ocupada pela barreira, como se o 
espaço de fase contivesse uma "memória" das propriedades exibidas com valores menores do parâmetro de controle. A região da fronteira apresenta a propriedade de stickiness, uma vez que órbitas que cruzam essa região ficam nela aprisionadas por um número grande de iterações.

O aprisionamento pode ser observado ainda na mesma figura 3.2(e). As orbitas que partem da condições iniciais $a$ e $b$ estão representadas pelos pontos em vermelho e verde, respectivamente. As duas órbitas ficam presas durante um grande número de iterações na região que lembra a barreira de transporte da figura 3.2(d). A região de stickiness é identificada pela área com elevada concentração de pontos, dentro da qual também se observam algumas ilhas.

Quando as órbitas $a$ e $b$ conseguem escapar, a primeira percorre apenas a área superior à região de stickiness, e a segunda, apenas a área inferior. As órbitas foram construídas com 6000 pontos cada uma, sendo necessárias mais iterações para que os pontos vermelhos e verdes ocupem todo o espaço de fase. Os pontos em preto da órbita $c$ se encontram acima e abaixo da região de stickiness, o que só foi possível com 42000 iterações (apenas os pontos a cada 7 iterações são exibidos). Até 24000 iterações, resultados numéricos mostram que a órbita $c$ ainda fica confinada à area acima da região de "stickiness".

Na figura 3.2(f), verifica-se não só a ausência da barreira de transporte como também da região de "stickiness". Duas órbitas, uma em vermelho (condição inicial no ponto $a$ ) e a outra em verde (condição inicial no ponto $b$ ), são mostradas e ambas percorrem toda a área do espaço de fase apresentada na figura. Embora não mais se observe uma região de "stickiness", o transporte entre as áreas superior e inferior ainda é difícil: os pontos em vermelho da órbita a se concentram mais em cima do que em baixo, e o contrário ocorre com os pontos em verde da órbita $b$. Ambas as órbitas são geradas com 6000 iterações.

Propriedades de transporte, como difusão e tempo de escape de trajetórias, apresentadas pelo mapa padrão não-twist após a quebra da barreira, são estudadas em [37]. Neste trabalho, resultados numéricos mostram que o efeito de aprisionamento das órbitas dentro da região de "stickiness" é fortemente influenciado pela presença de ilhas também dentro da mesma região. Quanto mais próximas das ilhas, maior é o número de iterações necessário para que as órbitas delas se afastem. 


\subsection{Mapa Modelo}

Do mesmo modo como fizemos nas seções anteriores, as figuras 3.3(a)-(d) e 3.4(a)(d), referentes ao mapa modelo, mostram mudanças essenciais que ocorrem no espaço de fase a partir de variações no parâmetro de controle. Como veremos, características similares aos do mapa padrão não-twist também estão presentes no mapa modelo. A

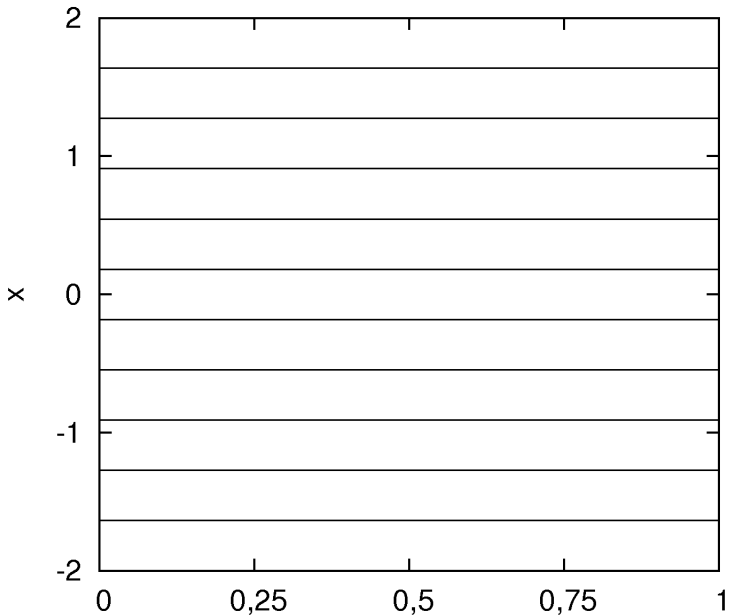

(a)

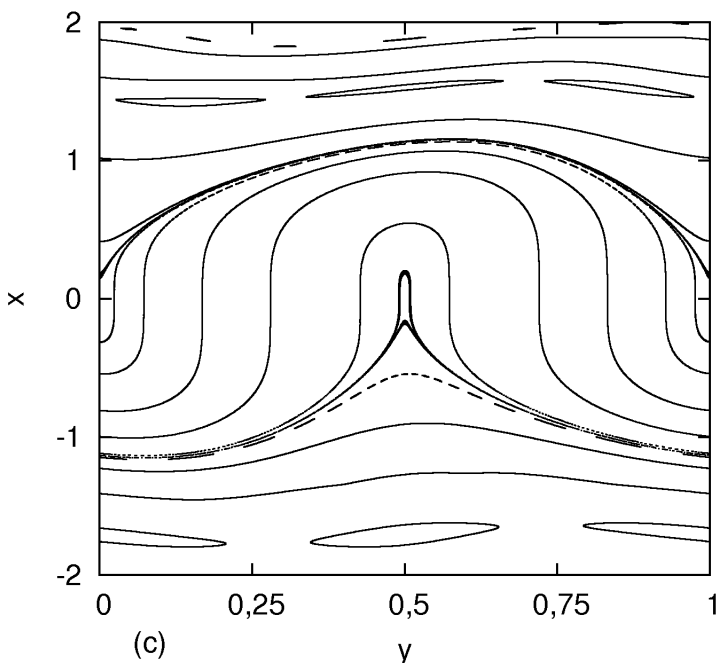

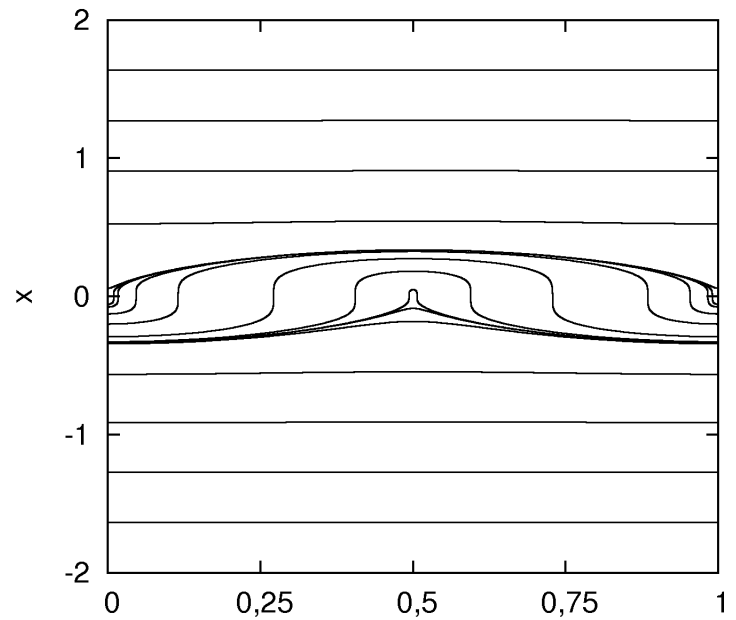

(b)

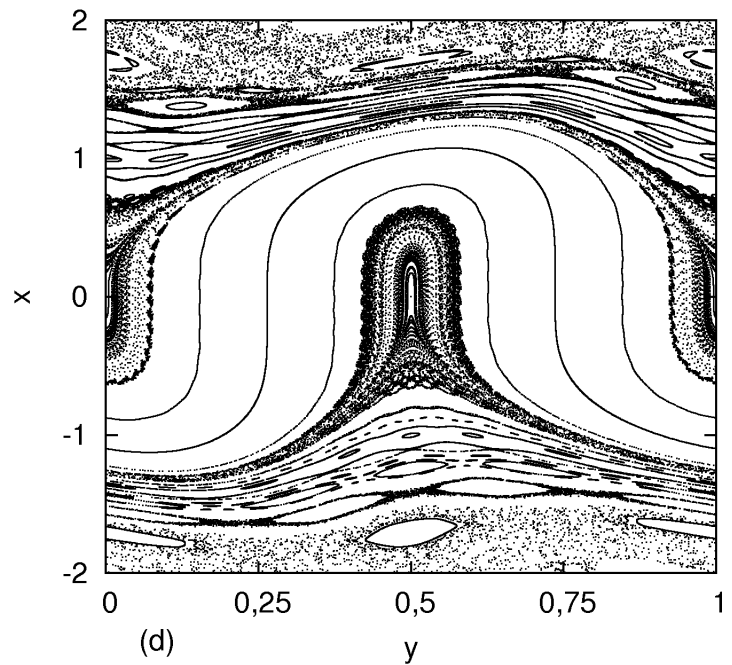

(d)

Figura 3.3: Mapa modelo para $b=0.1$. Parâmetro de controle: (a) $a=1 \times 10^{-7}$; (b) $a=0,001$; (c) $a=0,135 ;(\mathrm{d}) a=0,225$.

primeira semelhança se refere à função twist, que também possui perfil não-monotônico: $f(x)=b|x|^{3}$. Sem o módulo, o gráfico é um perfil monotônico com um ponto de inflexão em $x=0$. Usando o módulo, $x=0$ passa a ser um ponto de mínimo. Assim, na figura 


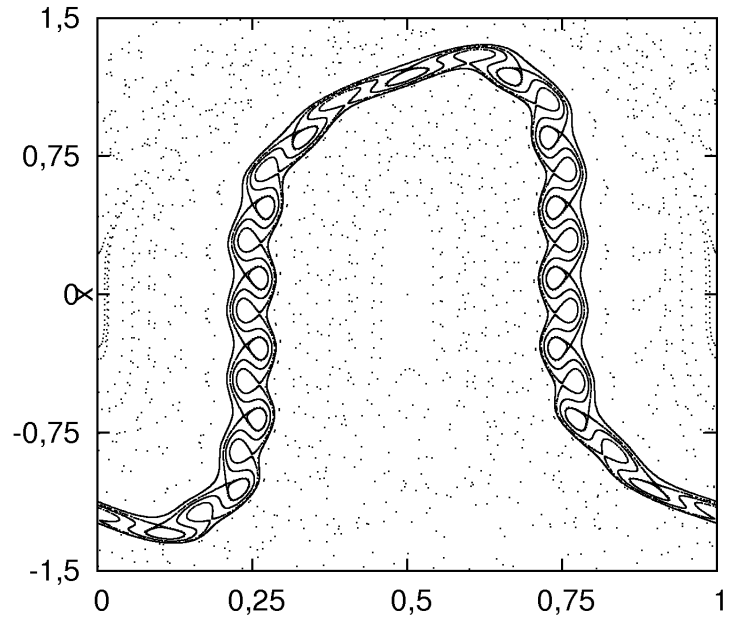

(a)

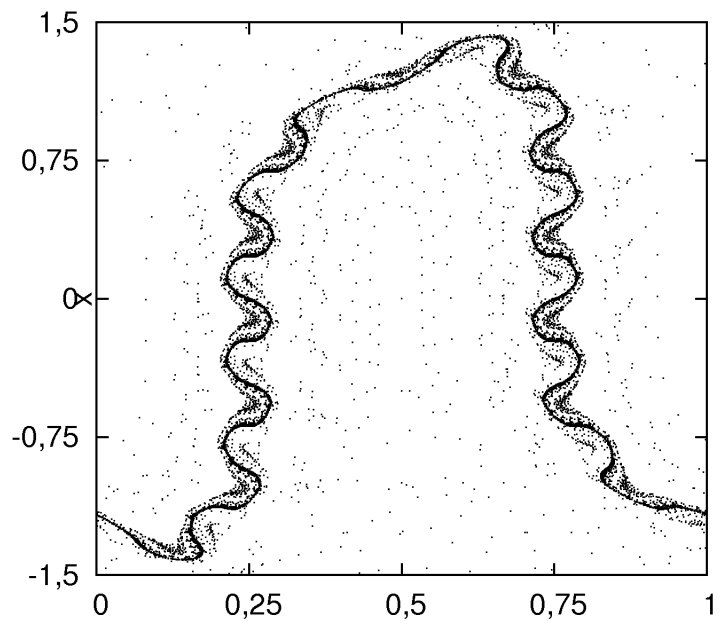

(c)

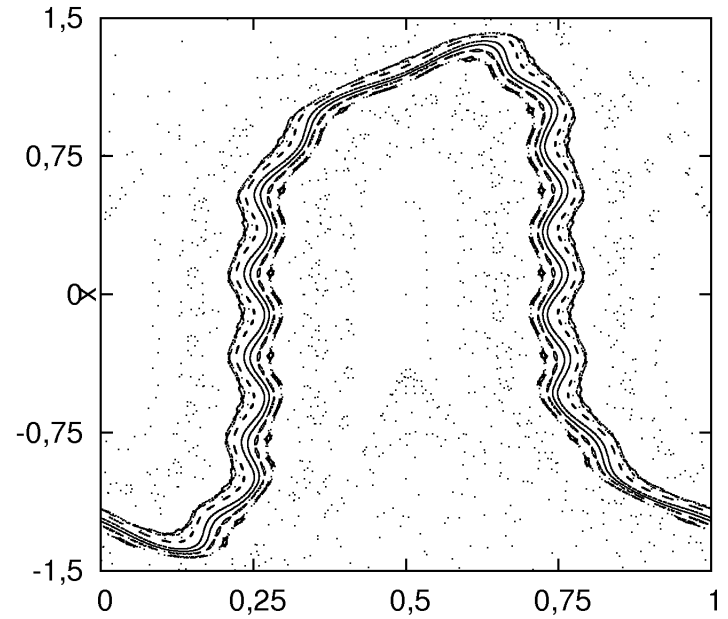

(b)

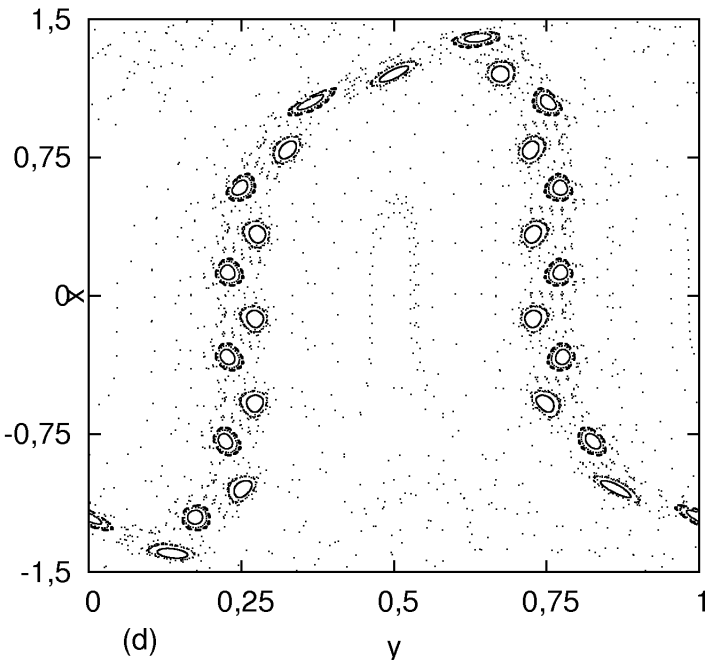

Figura 3.4: Barreira de transporte no mapa modelo. Parâmetros: (a) $a=0,384$; (b) $a=0,455$; (c) $a=0,460 ;$ (d) $a=0,464$. Para todos os casos, $b=0,1$. 
3.3(a), que corresponde ao caso para $a \approx 0$, o número de rotação das curvas invariantes cresce quanto mais distante se encontram da curva invariante central, localizada em $x=0$.

Para um valor maior do parâmetro de controle (ver fig.3.3(b)), as órbitas mais próximas da reta horizontal $x=0$ se deformam em torno dos pontos fixos $O_{1}=\left(x_{1}, y_{1}\right)$ e $O_{2}=$ $\left(x_{2}, y_{2}\right)$, onde $x_{1}=y_{1}=x_{2}=0$ e $y_{2}=0.5$. Os autovalores da matriz jacobiana, tanto em $O_{1}$ como em $O_{2}$, são ambos iguais a 1 . Neste caso, $O_{1}$ e $O_{2}$ são classificados como parabólicos.

Na figura 3.3(c), nenhuma alteração significativa é observada, exceto por algumas cadeias de ilhas que se tornam visíveis e pela expansão da área de curvas invariantes que contornam os pontos parabólicos. Regiões caóticas são evidentes na 3.3(d) e crescem nas áreas superior e inferior e em torno dos pontos parabólicos. O conjunto de curvas invariantes remanescentes indicam a formação de uma barreira de transporte, similar à encontrada no mapa padrão não-twist.

É o que se verifica na sequência de figuras 3.4(a)-(c), em que a barreira se encontra entre duas grandes regiões predominantemente caóticas. Experimentos numéricos conduzidos com o mapa modelo mostram não apenas a permanência da barreira para um amplo intervalo de controle como também o seu ressurgimento após a uma quebra eventual. O ressurgimento da barreira também ocorre para o mapa padrão não-twist.

Outra característica em comum se refere ao processo de reconexão dentro da barreira de transporte, que se pode observar no caso mostrado pela fig. 3.4(a). A formação de cadeias de ilhas e a configuração que assumem na região da barreira do mapa modelo será detalhadamente estudada no cap 4.

O aumento do parâmetro controle torna cada vez mais fina a barreira até que pouquíssimas curvas invariantes possam ser observadas antes da ruptura. As figs. 3.4(b)-(c) mostram o avanço das duas regiões caóticas. Observe-se também a ocorrência do fenômeno de stickiness, a partir da fig.3.4(c), na vizinhança de uma finíssima camada de curvas invariantes. Mesmo após a quebra da barreira (ver fig.3.4(d)), o stickiness ainda é encontrado em torno de cadeias de ilhas que permanecem visíveis para uma pequena variação do parâmetro. 


\subsection{Conclusão}

Apresentamos, neste capítulo, resultados numéricos obtidos através dos mapas padrão, padrão não-twist e modelo, sendo os dois últimos do tipo não-twist. Estes mapas, como foi possível verificar, provêm, de modo computacionalmente simples, informações sobre processos não-lineares que podem estar ocorrendo na borda do plasma.

A transição para o caos ocorre de modo distinto em cada um dos mapas, embora semelhanças possam ser observadas entres os mapas não-twist, particularmente no que se refere à formação de "meanders" e processos de reconexão, além das barreiras de transporte, que persistem mesmo com amplas variações do parâmetro de controle.

Nos casos não-twist, mesmo que a barreira não mais exista, o espaço de fase preserva uma espécie de "memória" das propriedades de transporte: duas regiões caóticas permanecem separadas por uma região intermediária. Para valores do parâmetro de controle menores que o de ruptura da barreira, a região intermediária está ocupada por curvas invariantes e cadeias de ilhas. Para valores maiores, a mesma região, caracterizada pela presença de ilhas isoladas em meio a órbitas caóticas, ainda dificulta o transporte, embora não o bloqueie completamente. 


\section{Capítulo 4}

\section{Cenários de Formação de Órbitas Periódicas}

Neste capítulo, vamos estudar o modo como se modifica a barreira de transporte do mapa modelo, apresentado no capítulo anterior, quando se altera apenas um de seus parâmetros: o parâmetro $a$, ao qual sempre faremos referência como parâmetro de pertubação ou controle. Os mapas obtidos a partir de um série de experimentos numéricos evidenciam que dois processos básicos ocorrem no interior da barreira. Estes processos, que chamaremos aqui de cenários par e ímpar, caracterizam-se pela formação de cadeias de ilhas no interior da barreira de transporte.

As cadeias estão associadas a orbitas de período par ou ímpar e possuem propriedades bem definidas, como, por exemplo, o fato de aparecerem sempre ao pares. Os resultados apresentados a seguir indicam que toda a dinâmica de alterações na topologia do espaço de fase, na regiao restrita à barreira de transporte, parece ser governada pela repetida emergência e destruição destas cadeias. Esse fenômeno é observado até a quebra da barreira de transporte, que persiste em intervalos significativos do parâmetro de controle enquanto uma ampla região do espaço de fase está tomada pelo caos.

Os fenômenos descritos neste capítulo não são exclusivos do mapa modelo: processos similares são encontrados em diferentes mapas do tipo não-twist [30,31,38-40]. Entre eles, podemos citar o mapa padrão não-twist, já discutido no capítulo 2. 


\section{1 Órbitas de Período Par}

As figuras 4.1(a)-(d) mostram o cenário de formação de órbitas de período par ou, simplesmente, cenário par, para valores crescentes do parâmetro de controle. Inicialmente, não se observa nenhuma cadeia de ilhas dentro da barreira, mas com pequenos aumentos no parâmetro, as órbitas na região mais interna da barreira começam a se deformar até que surgem duas cadeias de dezesseis ilhas cada uma.

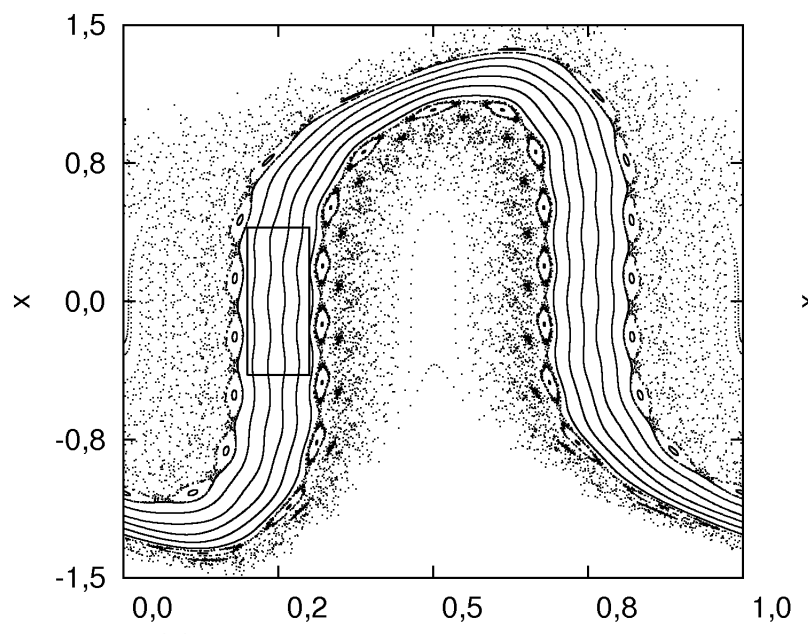

(a)

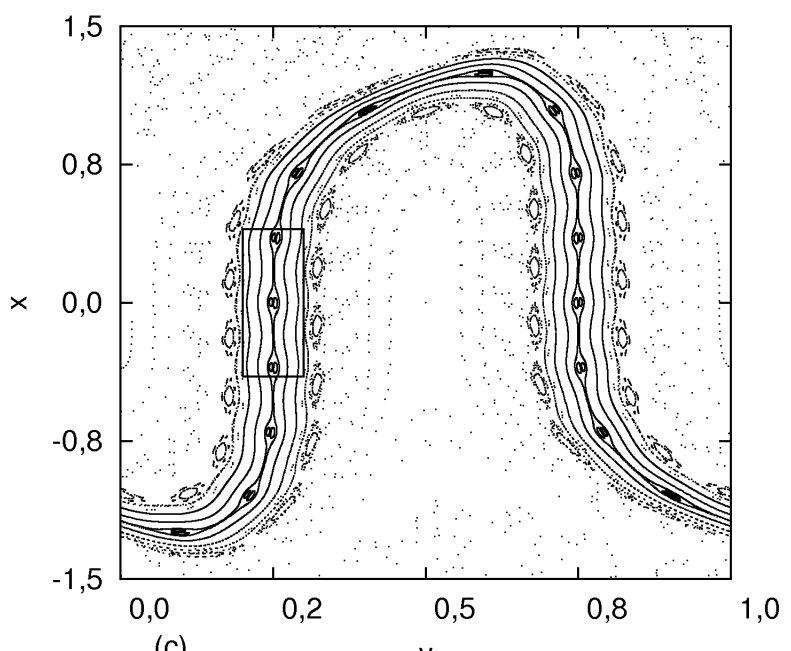

(c)

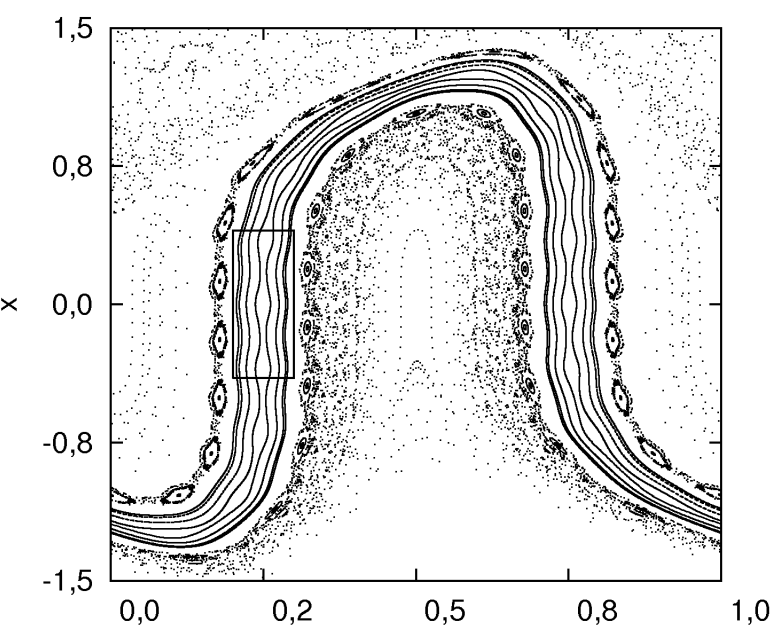

(b)

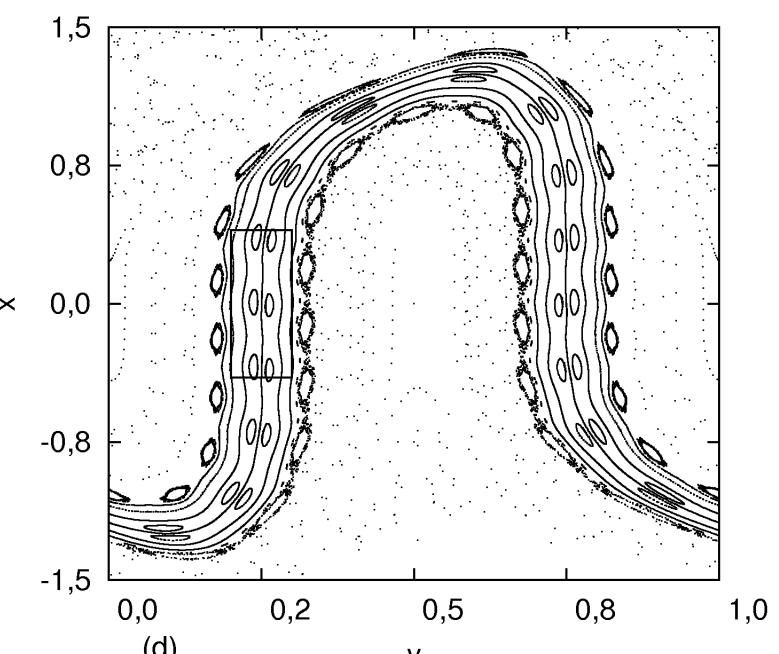

(d)

Figura 4.1: Cenário par: formação de um par de cadeias com 16 ilhas cada uma. Parâmetros do mapa: (a) $a=0.351$; (b) $a=0.3518$; (c) $a=0.352$;(d) $a=0.3529$. Para todos os casos, $b=0.1$.

Mais detalhes podem ser vistos a partir das ampliações das áreas retangulares, mostradas nas figuras 4.2(a)-(d). As trajetórias, durante a evolução do cenário, deformam-se 
continuamente, o que corresponde à formação dos meanders. Como vimos no capítulo 3 , essas curvas também aparecem no mapa padrão não-twist.
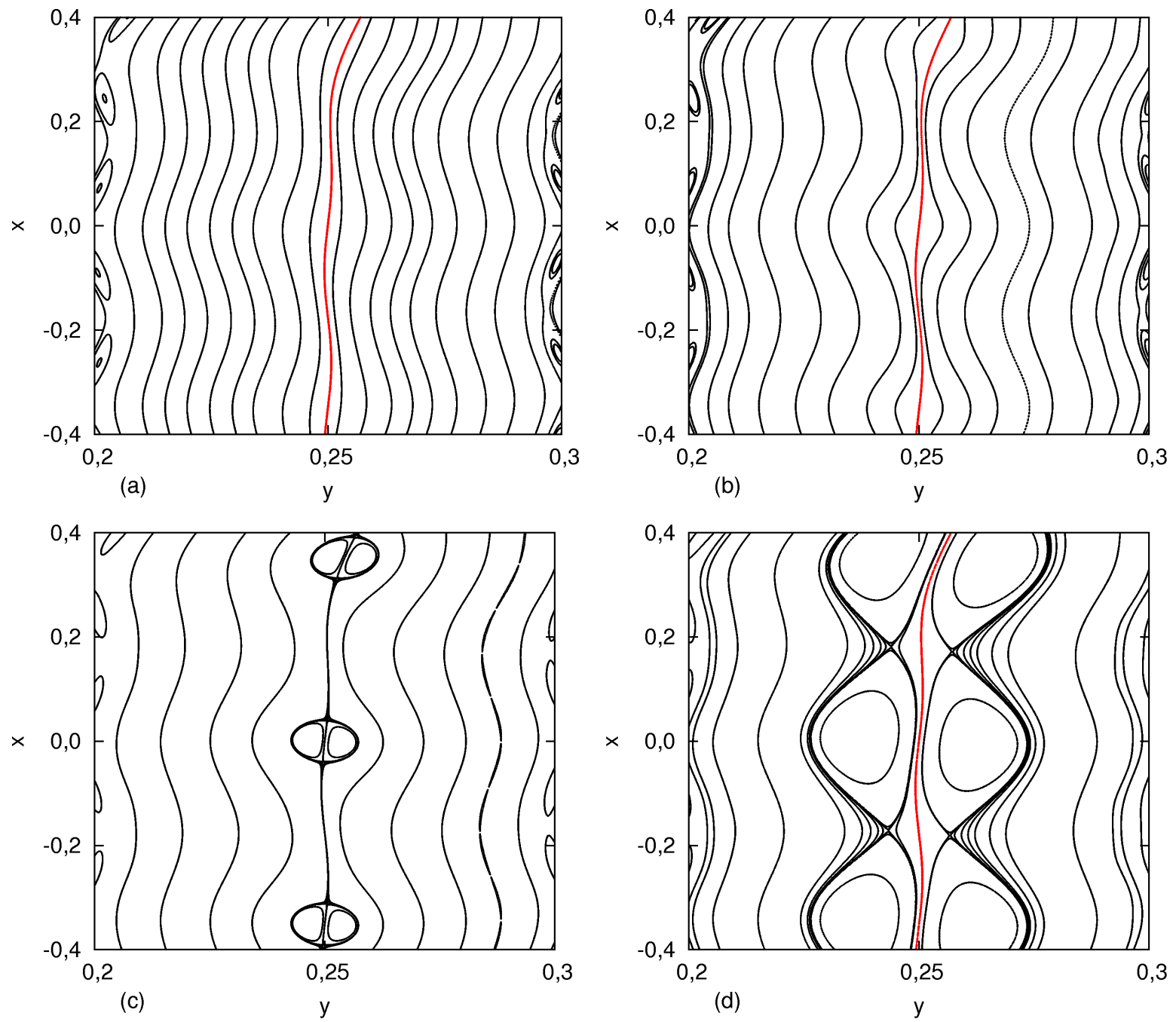

Figura 4.2: Ampliação das regiões delimitadas pelo retângulos das figuras 4.1(a)-(d). (a) Início da formação dos "meanders". A linha em vermelho representa a curva "shearless". (b) É possível que, para este parâmetro, o nascimento das ilhas tenha ocorrido embora ainda não sejam visíveis. Observas-se que aumenta a deformação dos "meanders".(c) Cadeias de ilhas aparecem ligadas, e nenhuma curva "shearless" é observada. (d) As cadeias de ilhas se separam e se movem para o mar caótico. Uma curva "shearless" reaparece na região mais interna da barreira.

As figuras 4.2(a)-(b) descrevem uma das seguintes situações: na primeira, as ilhas ainda não surgiram, mas o nascimento está para ocorrer; na segunda, o nascimento deve ter ocorrido, mas devem estar muito pequenas. Nas figuras 4.2(c) e 4.2(d), as cadeias já são evidentes. A simetria inerente ao processo sugere a ocorrência de duas bifurcações. 
Na primeira, uma órbita dá origem a outras duas, gerando pares de pontos elípticos. As ilhas se mantêm coladas (fig. 4.2(c)) para um certo intervalo de variação do parâmetro até que, na segunda bifurcação, pontos hiperbólicos se duplicam. As cadeias de ilhas estão, a partir daí, separadas (fig. 4.2(d)).

Com o aumento do parâmetro de controle, as ilhas ficam cada vez maiores, assim como a separação entre elas, até que se desprendem da barreira, lançando-se à região caótica. Para um valor ainda maior do parâmetro, elas são destruídas. Isso ficará evidente com resultados apresentados na seçao 4.4 .

\section{2 Órbitas de Período Ímpar}

Nas figuras 4.3(a)-(d), observa-se o surgimento de duas cadeias com quinze ilhas cada uma. Ao cenário de formação de órbitas de período ímpar, faremos referência, simplesmente, como cenário ímpar. Detalhes das regiões delimitadas pelo retângulos são mostrados nas ampliações 4.4(a)-(d). As curvas mais internas se deformam significativamente à medida em que se aumenta o parâmetro de pertubação. Trata-se, novamente, dos meanders, como podemos ver nas figuras 4.3(a) e 4.4(a).

As figuras 4.3(b) e 4.4(b) retratam a barreira após o nascimento das ilhas, que são contornadas pelos meanders mais internos. Para cada ilha, observam-se órbitas homoclínicas e heteroclínicas. Aumentando-se o parâmetro de pertubação, a espessura da região formada por esses meanders mais internos torna-se cada vez menor até que, como mostram as figuras 4.3(c) e 4.4(c), as duas cadeias estejam conectadas através das separatrizes. Este processo, que se costuma chamar de reconexão, foi discutido, no capítulo 3, para o caso do mapa padrão não-twist.

Aumentando-se novamente o parâmetro (ver figuras 4.3(d) e 4.4(d)), as cadeias se desconectam e, assim como no cenário par, deslocam-se até a periferia da barreira. Este deslocamento das ilhas, em ambos os cenários, ocorre simultaneamente ao avanço da região caótica sobre a barreira de transporte: as cadeias nascem, movem-se para fora, e a barreira torna-se cada vez menos espessa até que ocorra sua ruptura. 

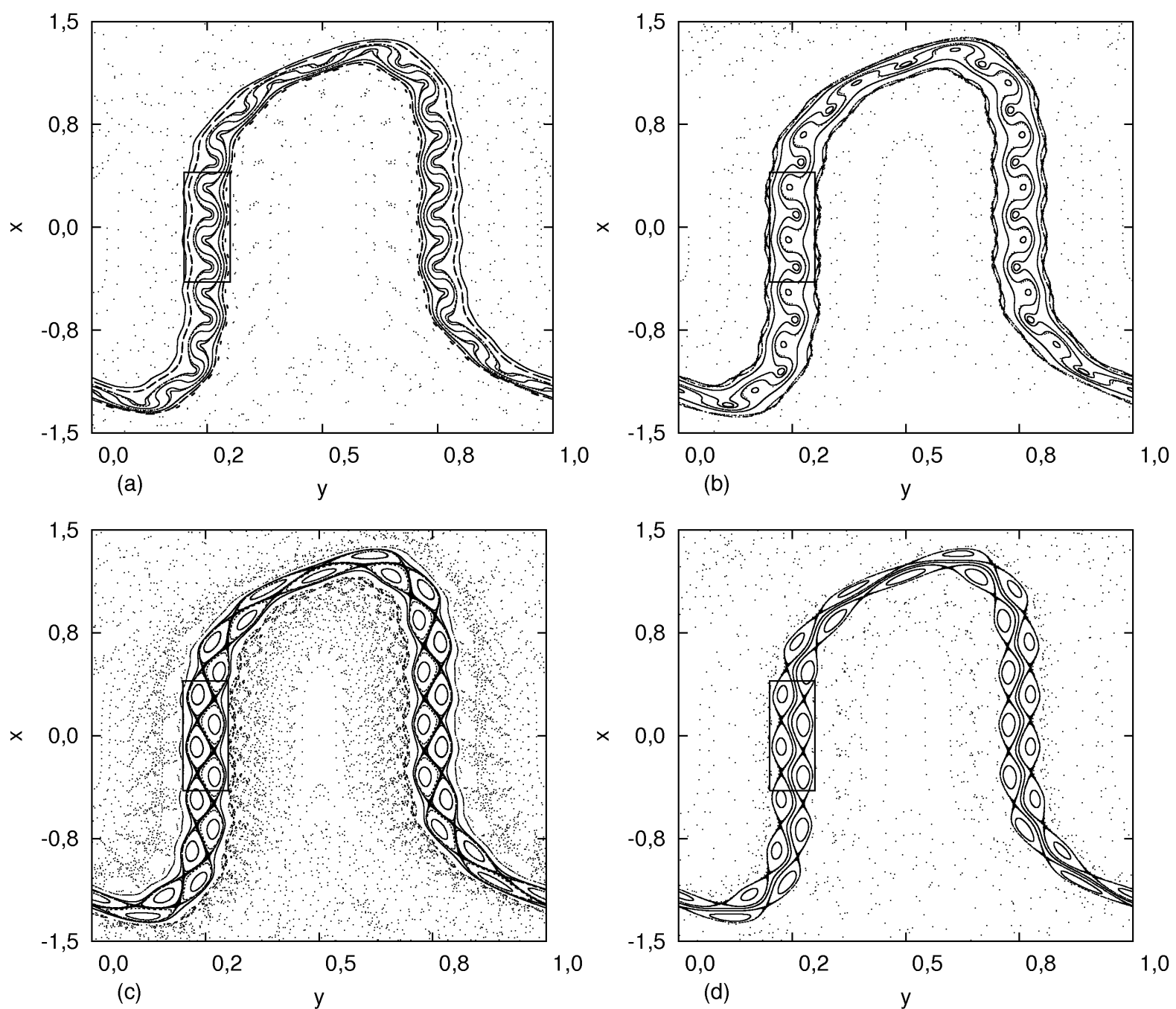

Figura 4.3: Cenário ímpar: nascimento de um par de cadeias com 15 ilhas cada uma. Parâmetros do mapa: (a) $a=0.383$; (b) $a=0.3835$; (c) $a=0.38539$; (d) $a=0.3865$. Para todos os casos, $b=0.1$.

\subsection{Números de Rotação e Curvas "Shearless"}

Nesta secção, vamos analisar ambos os cenários através do cálculo de números de rotação, cuja definição apresentamos no capítulo 2. Os mesmos valores para o parâmetro de pertubação serão utilizados. Mostraremos que este cálculo é um instrumento importante para se descrever algumas das propriedades do mapa modelo. Nas mesmas regiões do espaço de fase referentes às figuras 4.2(a)-(d) e 4.4(a)-(d), construímos uma grade de condições iniciais. Para cada ponto dessa grade, formada por 360000 pontos $(600 \times 600)$, calcula-se o número de rotação. Uma escala de cores é adotada, de modo que possamos 

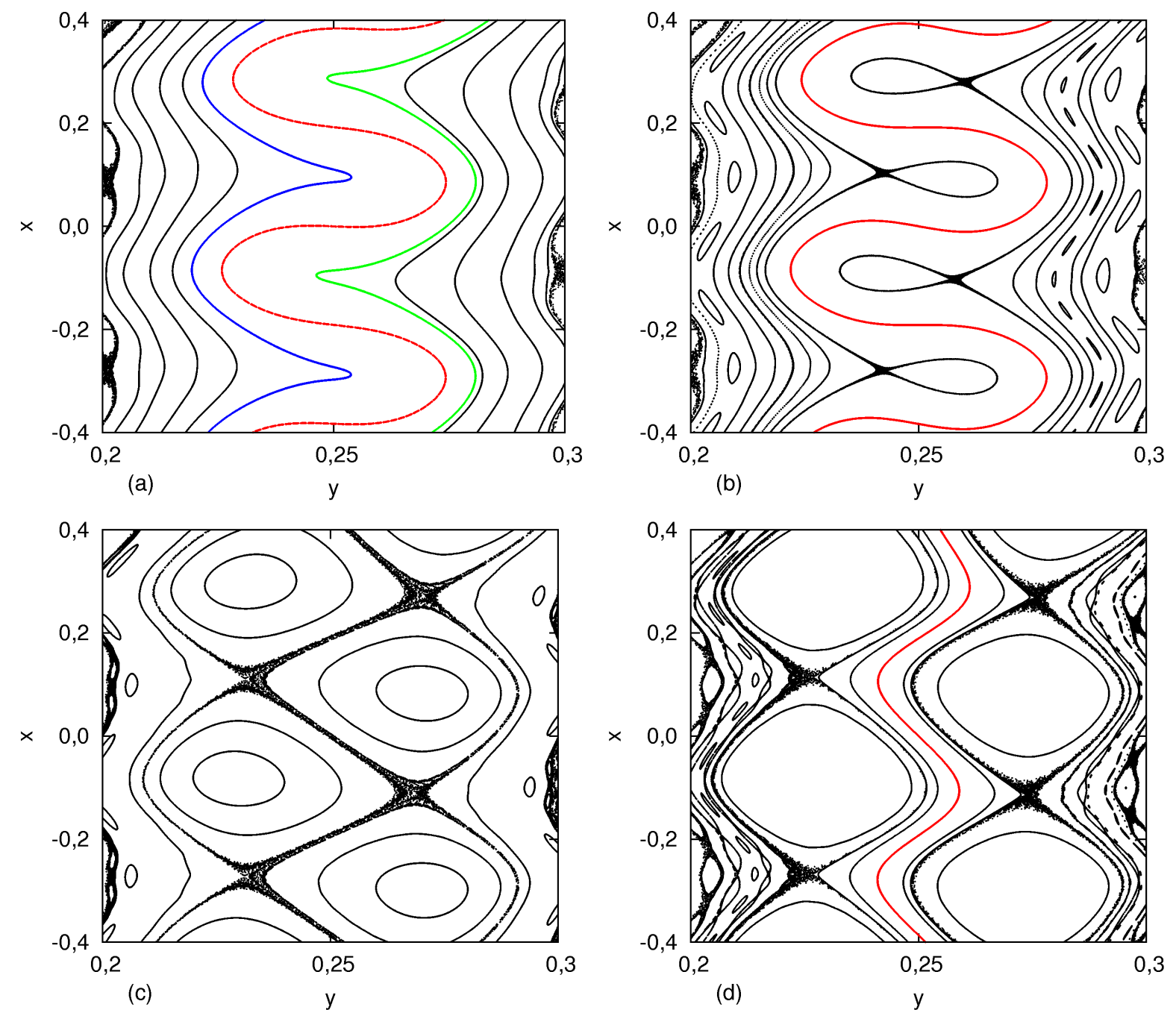

Figura 4.4: Ampliação das áreas retangulares das figuras 4.3(a)-(d). (a) Formação dos meanders e presença de três curvas "shearless", as curvas em azul, vermelho e verde. (b) Antes da reconexão, cadeias de ilhas substituem duas das curvas "shearless" anteriores, as curvas em azul e verde; (c) As cadeias estão ligadas e não se observa nenhuma curva "shearless". (d) Após a reconexão, as cadeias se deslocam para fora da barreira (regiões caóticas) e uma única curva "shearless", a curva em vermelho, reaparece.

analisar como o número de rotação varia dentro da região de interesse. Os resultados são apresentados nas seções 4.3.1 e 4.3.2.

Devido a variações muito pequenas entre os valores obtidos, é necessário aplicar um método de normalização para que as estruturas presentes nas figuras possam ser visualizadas com clareza. Os números de rotação $(\omega)$ são normalizados em relação ao valor 
máximo $\left(\omega_{\max }\right)$, de acordo com a seguinte fórmula:

$$
\omega_{\text {norm }}=\left(\frac{\omega}{\omega_{\max }}\right)^{n}
$$

onde $\omega_{\text {norm }}$ é o número de rotação $\omega$ normalizado e $n$, que chamaremos de expoente de normalização, dever ser sempre maior que um. Assim, quanto maior o valor do expoente de nomalização, se $\omega_{\text {norm }}$ estiver próximo da unidade, este valor ficará ainda mais próximo. E se $\omega_{\text {norm }}$ for quase igual a zero, aumentos em $n$ aproximam $\omega_{\text {norm }}$ ainda mais desse valor. A aplicação da fórmula 4.1 resulta, portanto, em conferir variações mais significativas entre os números de rotação e as cores que são usadas para representá-los.

\subsubsection{Cenário Par}

Nas figuras 4.5(a)-(d), vemos que os números de rotação reproduzem as cadeias de ilhas que caracterizam o cenário par. Dentro das ilhas, o número de rotação é constante, já que não se percebe nenhuma variação na cor. Fora delas, os valores decrescem suavemente da região mais interna até as bordas laterais da barreira. Se imaginamos uma superfície em um sistema de coordenadas tridimensional, tendo o número de rotação $\omega$ como eixo vertical, e as coordenadas $x$ e $y$ como eixos horizontais, esta superfície lembra a forma de uma cordilheira. O trajeto dessa cordilheira coincide com o da barreira de transporte no espaço de fase. As órbitas mais internas da barreira percorrem o seu topo, e as ilhas correspondem a plataformas incrustadas na sua superfície. Para efeito de concisão, a cada momento em que fizermos referência a essa superfície de números de rotação, usaremos o símbolo $S_{\omega}$.

Um outro modo de se analisar a topologia de $S_{\omega}$ é seccioná-la com planos paralelos ao eixo $\omega$. Esses planos verticais geram perfis como os das figuras 4.6(a)-(d). O eixo $\omega$ exibe os valores reais, não sendo necessária a normalização. Os perfis foram traçados a partir de condições iniciais localizadas sobre o segmento de reta $\{x=0 ; 0.2 \leq y \leq 0.3\}$. Esta linha é mostrada na fig.4.5(a). Cada um dos perfis, portanto, encontra-se na intersecção entre a superfície $S_{\omega}$ e um plano que, além de cortar o eixo $x$ na origem, é paralelo aos eixos $\omega$ e $y$.

Nos perfis das figuras 4.6(a), 4.6(b) e 4.6(d), podemos ver pontos de máximo onde o 


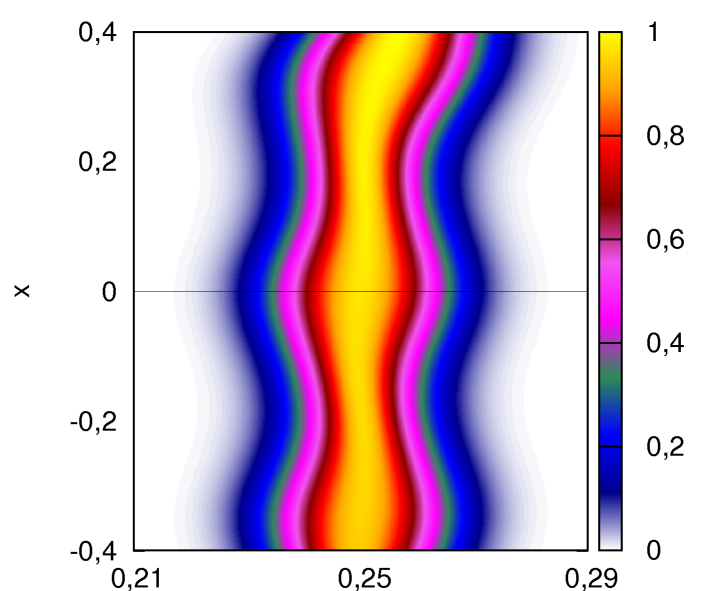

(a)

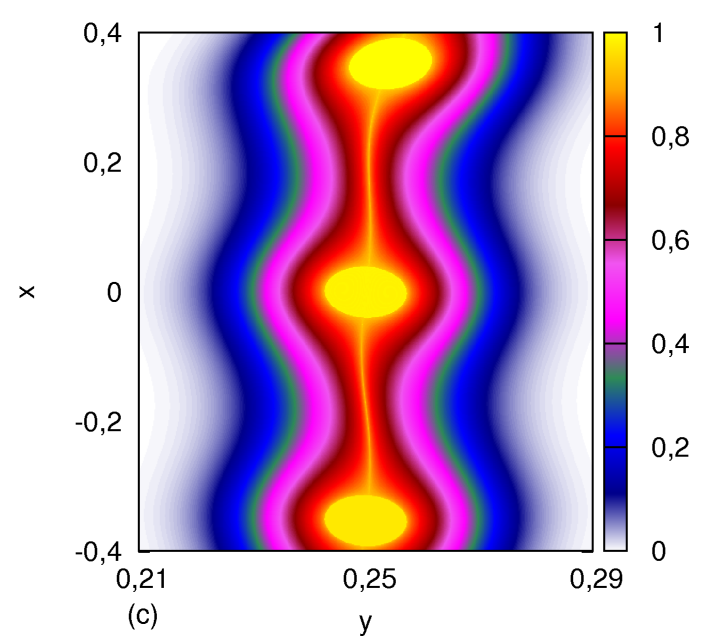

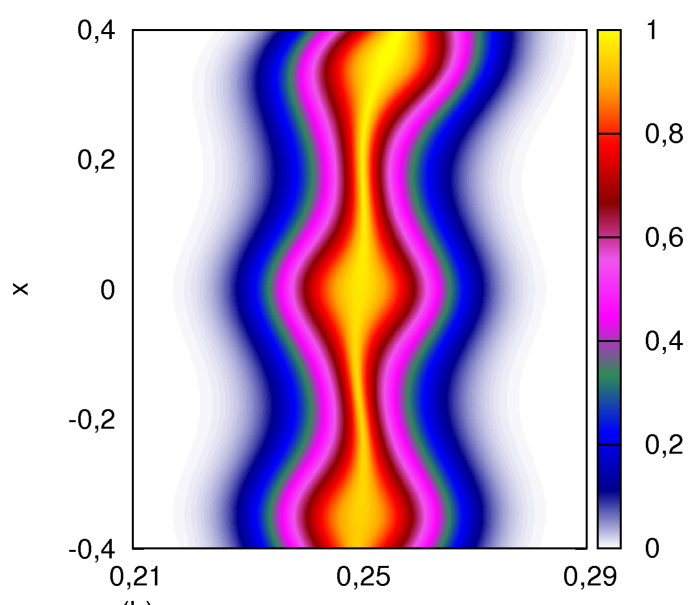

(b) $\quad y$

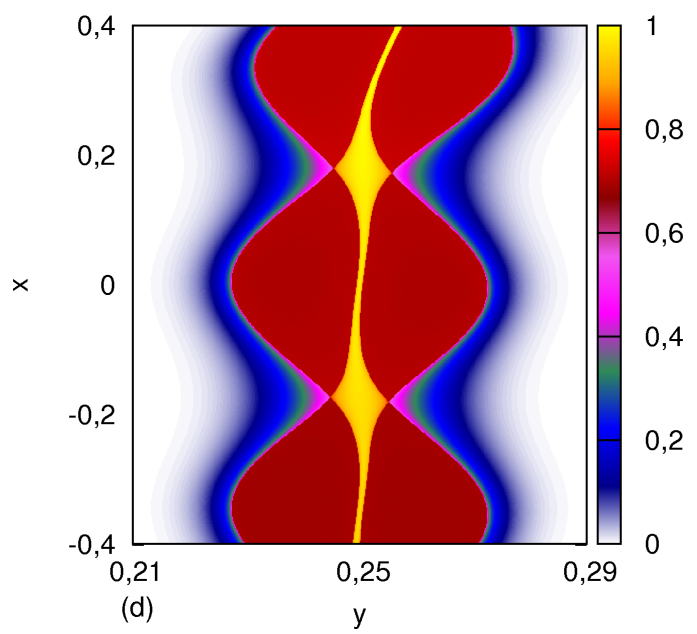

Figura 4.5: Números de rotação para o cenário par: a sequência de parâmetros adotada e a área em que os números são calculados são as mesmas da fig.4.2. Os números estão normalizados de acordo com a equação 4.1. Observa-se que as órbitas têm números de rotação maiores nas regiões mais internas da barreira (regiões em amarelo), que possuem os pontos mais elevados em $S_{\omega}$. Nos casos (a), (b) e (d), quanto mais interna a órbita, mais próxima ela se encontra da curva "shearless". Na figura (c), o par de cadeias pares, que estão conectadas, forma "plataformas" nos pontos mais de $S_{\omega}$. Neste caso, não se tem nenhuma curva "shearless".

número de rotação varia de forma suave. A presença desses pontos nos leva à definição de curva shearless, que corresponde a órbita formada por pontos extremos, sejam eles de máximo ou de mínimo, nos quais ocorrem variações suaves do número de rotação sobre a superfície $S_{\omega}$.

Imaginando novamente as superfícies $S_{\omega}$ para as figuras que compõem esse cenário, vemos que a curva shearless é a linha que percorre o topo da cordilheira. Esse topo tem altura constante, pois é percorrido por uma única órbita, ao longo da qual o número de 

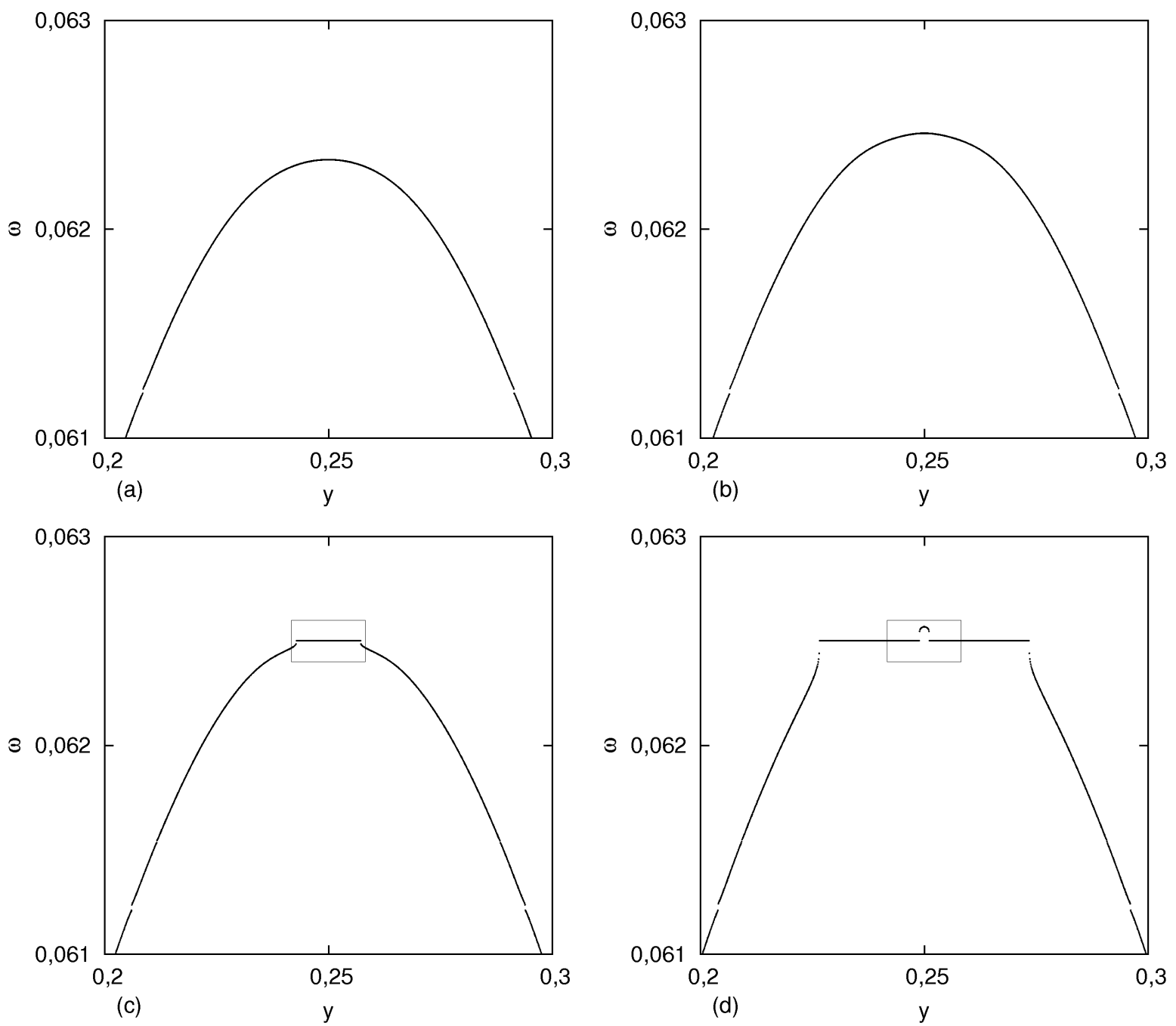

Figura 4.6: Perfis de $\omega$ para o cenário par sobre a reta $x=0$. Valores do parâmetro de controle são os mesmos da fig.4.2.

rotação não pode variar.

O plano de corte que gera os graficos 4.6(a) e 4.6(b) não intercepta ilhas de tamanho perceptível, o que se verifica pela ausência de patamares ao longo das curvas. Os dois casos ilustram os perfis que precedem o nascimento das ilhas descritos na seção 4.1. Porém, essas ilhas se tornam evidentes na figura 4.6(c) com a formação de um patamar onde antes se encontrava um ponto da curva shearless, ou, simplesmente, ponto shearless.

Com o aumento do parâmetro de pertubação, verifica-se a situação posterior à separação dos pares de cadeias: o que parecia ser um único patamar agora são dois, separados por um novo ponto shearless, como podemos ver na figura 4.6(d). Ampliando as 
áreas retangulares das figuras 4.6(c)e 4.6(d), vemos com mais detalhe esse processo (ver figs.4.7(a)-(b)).
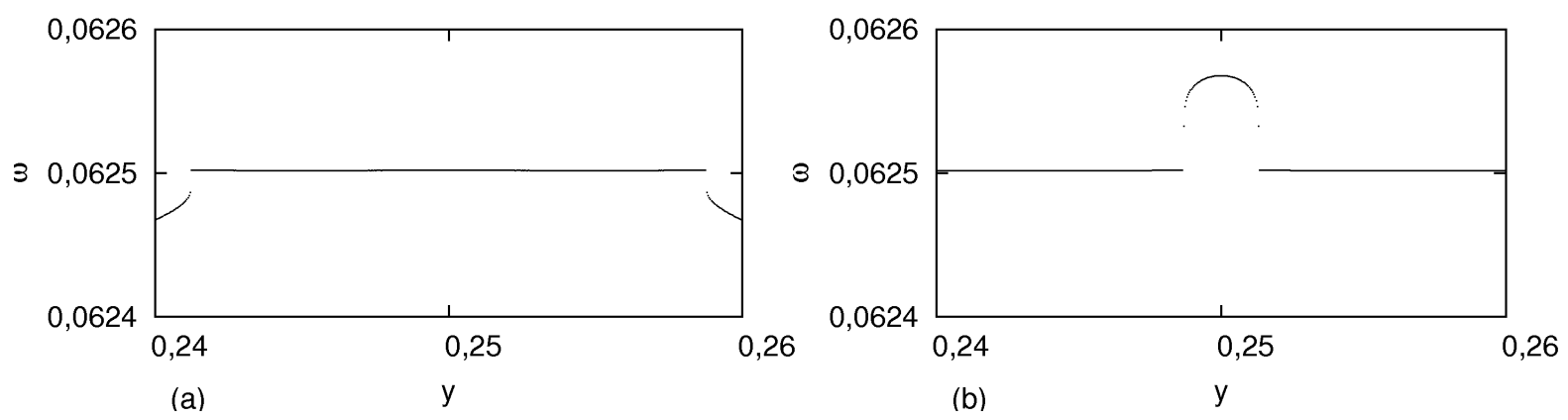

Figura 4.7: Ampliação das áreas retangulares das figuras 4.6(c)-(d): sobre o patamar, forma-se um novo ponto de máximo, correspondente a uma nova curva shearless.

\subsubsection{Cenário Ímpar}

As figuras 4.8(a)-(d) reproduzem as cadeias de ilhas características do cenário ímpar. Perfis de números de rotação podem ser vistos nas figuras 4.9(a)-(d). As condições iniciais que geram os perfis encontram-se sobre o segmento de reta $\{x=-0.1 ; 0.2 \leq y \leq 0.3\}$, indicado na fig.4.8(a).

Ainda na mesma figura, o número de rotação cresce, na direção $y$, das laterais para o centro. No entanto, a área ocupada pelos meanders mais internos indica a presença de um vale, dentro qual o número de rotação varia muito pouco, próximo do valor 0.6 da escala cores (cor púrpura). Já os meanders que percorrem as bordas do vale (regiões em amarelo), possuem os maiores números de rotação. Verifica-se, assim, que a superfície de números de rotação possui três curvas shearless: uma no fundo vale, e as outras duas, os meanders mais elevados, nas bordas. Isso é evidente no perfil da figura 4.9(a), em que se observam três pontos shearless, um de mínimo e dois de máximo. Na próxima seção, mostraremos como nascem essas três curvas shearless.

No segundo caso, ilustrado através da figura 4.8(b), ainda se vê a presença de um vale (região em azul; na escala de cores, valores próximos a 0.2). Nas regiões em amarelo, observam-se as cadeias de ilhas, cujas órbitas heteroclínicas ocupam o local em que antes se encontravam as curvas shearless de máximo número de rotação. O perfil correspon- 


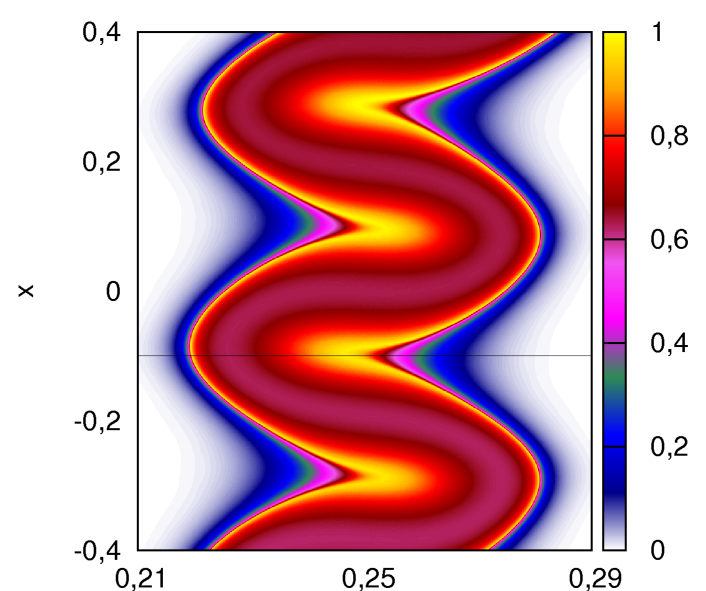

(a)

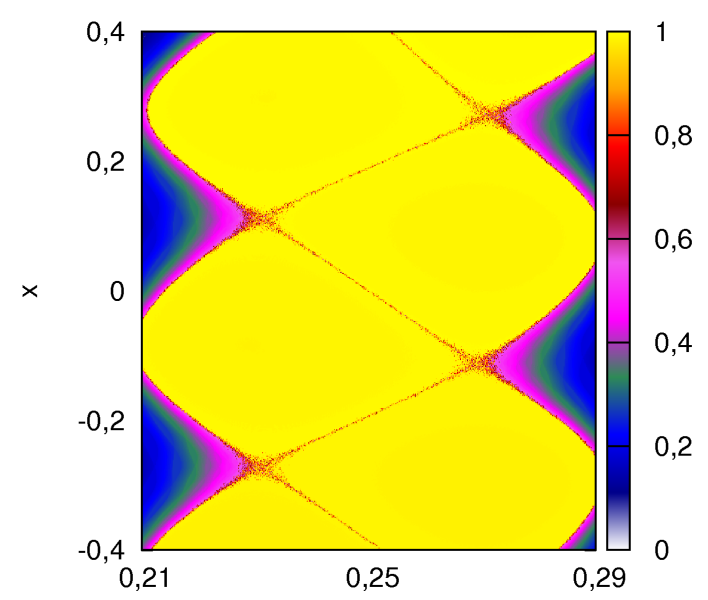

(c)

y

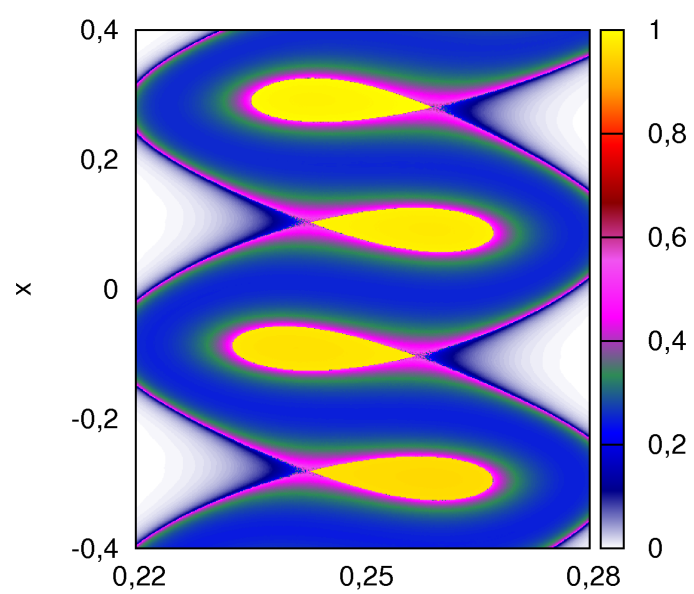

(b)

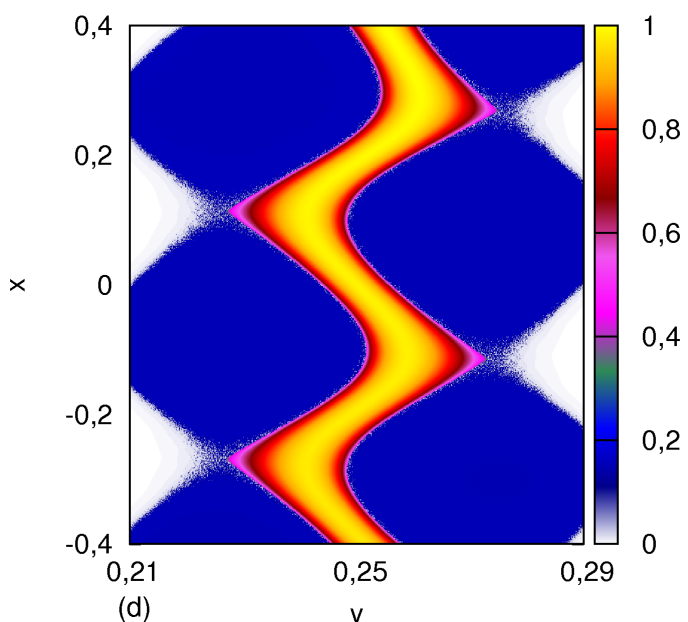

(d)

Figura 4.8: Números de rotação para o cenário ímpar. Os valores dos parâmetros são os mesmos da fig.4.4. (a) Formação de um "vale" nos meanders mais internos (regiões em púrpura), localizados entre dois topos "shearless" (regiões em amarelo). (b) Nascimento do par de cadeias ímpares ("plataformas" em amarelo) nas áreas mais elevadas. (c) Desaparecimento do "vale": par de cadeias conectadas. (d) Separação das cadeias e reaparecimento de um topo "shearless" nos "meanders" mais internos.

dente (fig.4.9(b)) possui um ponto shearless de mínimo, além de um patamar associado à intersecção entre o plano de corte e uma ilha. A curva apresenta descontinuidade em ambos os extremos do patamar. Em um deles, verifica-se uma forte instabilidade numérica. Isso se deve ao fato de que o perfil cruza uma região próxima à variedade de um ponto hiperbólico. Tais regiões se mostram caóticas, e nelas o número de rotação não está definido. Esse fato se manifesta na instabilidade dos números de rotação obtidos numericamente. Além de variarem de maneira abrupta e irregular diante de pequenas alterações nas condições iniciais, eles podem ser muito maiores ou menores em relação 

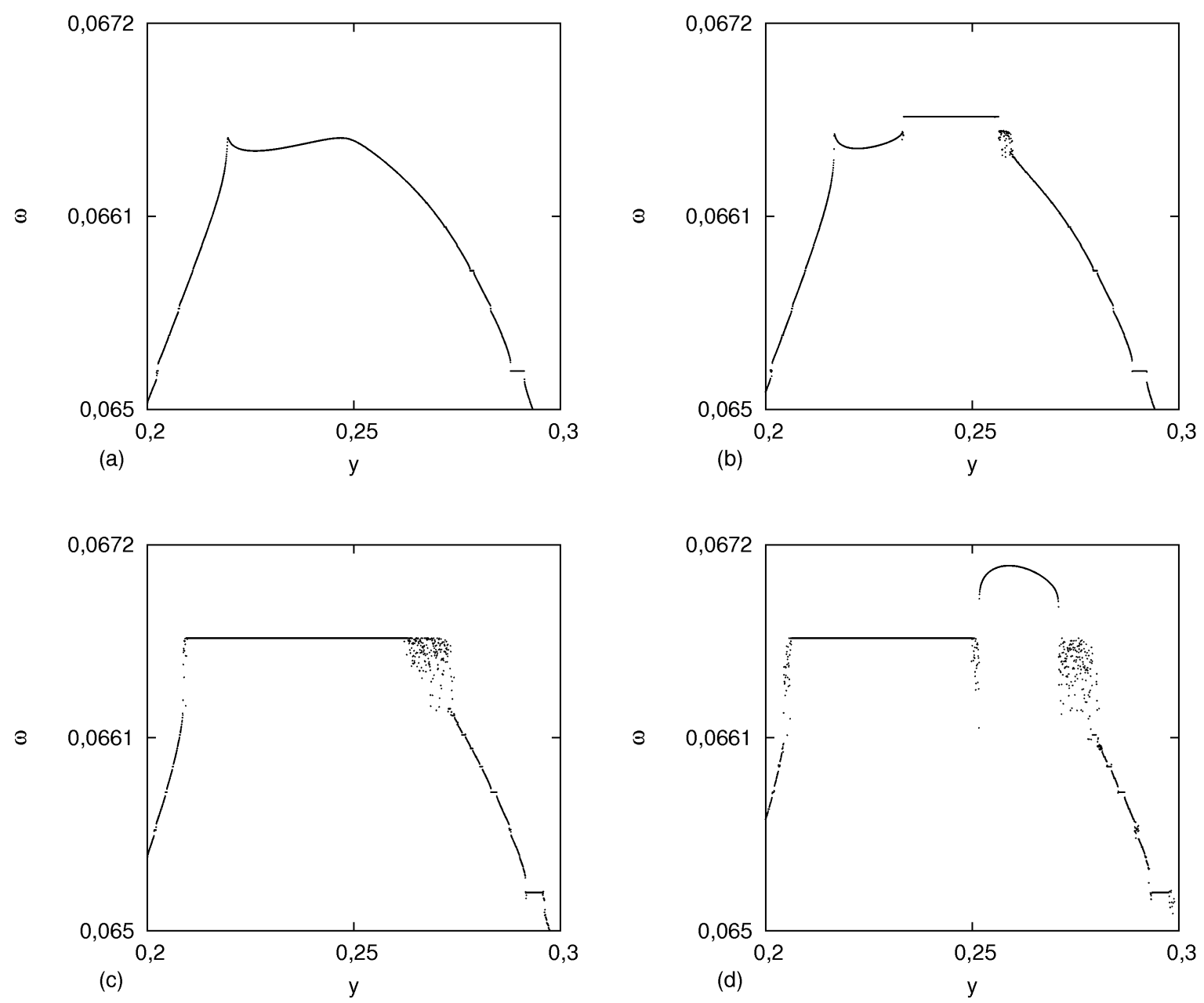

Figura 4.9: Perfis de números de rotação para o cenário impar. Condições iniciais sobre a reta $x=-0.1$. Analisados em conjunto com os casos apresentados na figura 4.8, os perfis ajudam a entender as formas da superfície de $S_{\omega}$.

à média, ficando fora do limites do gráfico. Isso explica porque alguns pontos não são mostrados, tornando o perfil descontínuo.

A figura 4.8(c) mostra o momento da conexão das separatrizes. A área exibida é, praticamente, toda ocupada por ilhas, nas quais o número de rotação também é máximo. Não são observados vales ou topos com variações suaves, o que é confirmado pelo perfil da figura 4.9(c). Vemos, portanto, que não existem curvas shearless neste caso (a separatriz é comum às duas cadeias). Mas após a separação das cadeias (ver figs.4.8(d) e 4.9(d)), surge entre elas uma elevação e em seu topo uma nova curva shearless. 


\subsubsection{Bifurcação da Curva Shearless}

Na seção 4.3.1, as imagens 4.5(d) e 4.6(d) indicaram o aparecimento de uma curva shearless. Com o aumento do parâmetro de controle, a região do espaço de fase em torno da curva shearless se amplia, e o perfil 4.6(d) cresce até assumir a forma mostrada na imagem 4.10(a).
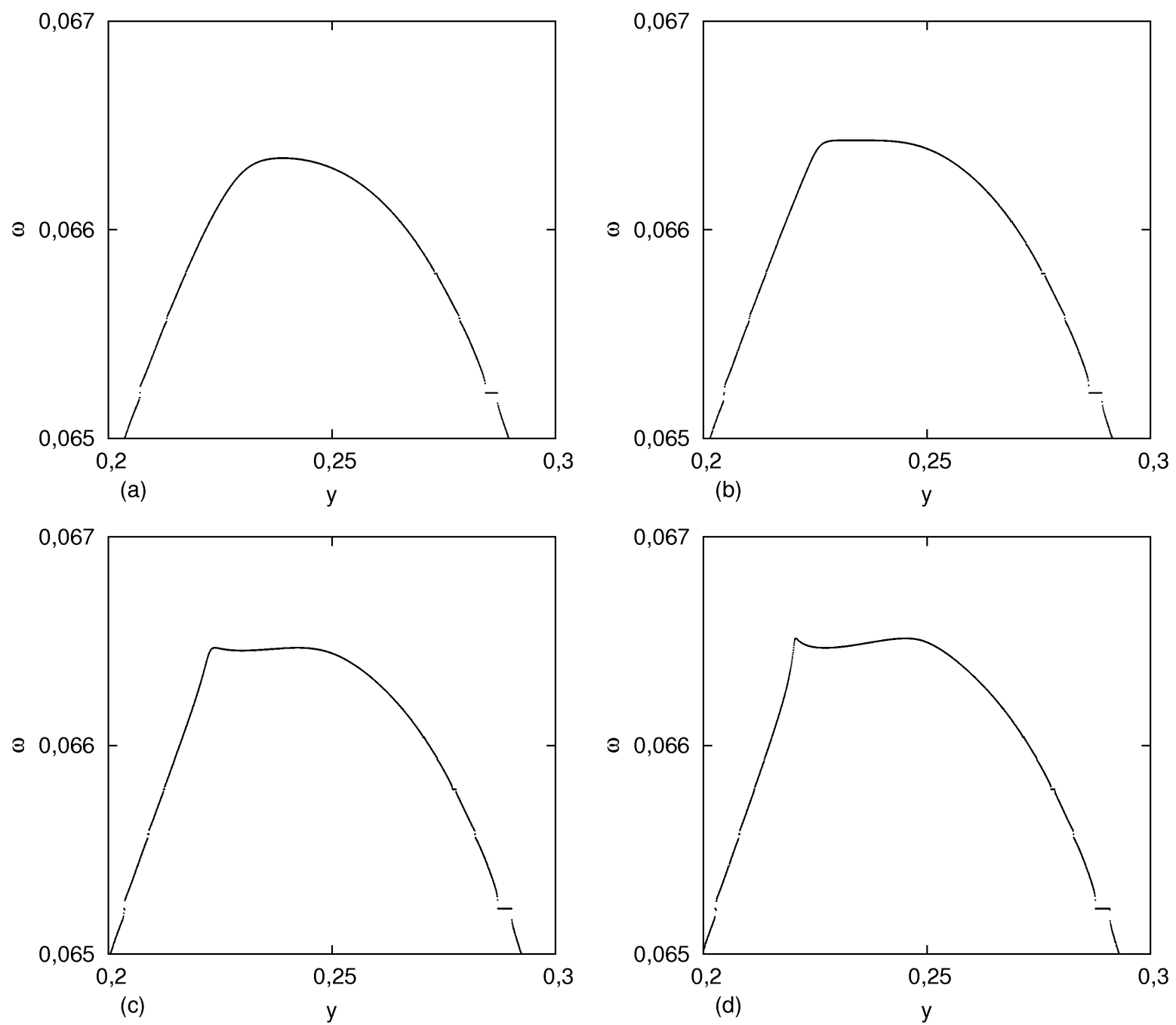

Figura 4.10: Bifurcação da curva shearless. (a) O perfil um único ponto "shearless" de máximo $(a=0.381)$. (b) "Achatamento" na vizinhança do ponto de máximo $(a=0.382)$. (c) Formação de três pontos "shearless": dois de máximo e um de mínimo ( $a=0.3825)$. (d) Aumento da profundidade do "vale" em $S_{\omega}(a=0.38285)$. Para um valor um pouco maior do parâmetro, nascem as cadeias ímpares.

Ainda há apenas um ponto shearless, mas, na sua vizinhança, o perfil tende a ficar achatado (ver fig.4.10(b)). Aumentando o parâmetro de controle, observa-se uma defor- 
mação na região mais alta do perfil, como se pode verificar na figura 4.10(c). O resultado é o aparecimento de um ponto de mínimo e dois pontos de máximo. No perfil 4.10(d), a deformação se acentua, e, com um aumento bastante pequeno na pertubação, o perfil é o mesmo que apresentamos figura 4.9(a).

Na seção 4.3.2, descrevemos, através da imagem 4.8(a), a superfície $S_{\omega}$ associada a esse perfil. Três curvas shearless foram identificadas: uma no vale da superfície, e as outras duas nas regiões mais elevadas (topos). Torna-se evidente, assim, que o processo de deformação observado nas figuras 4.10(a)-(b), que corresponde à formação dos topos e do vale em $S_{\omega}$, é responsável pela bifurcação da curva shearless. Para um certo valor do pârametro de controle, no local onde se encontra um única curva shearless, outras três se originam. Essas curvas vão se afastando uma da outras até que nascem as cadeias de ilhas características do cenário ímpar.

\subsection{Nascimento de Órbitas Periódicas}

Nas seções 4.1 e 4.2, vimos que dois processos de formação de órbitas periódicas ocorrem no interior da barreira de transporte, os cenários par e ímpar. As cadeias de ilhas assumem configurações bem definidas, como mostramos nas figuras 4.1 e 4.3. Nesta seção, apresentamos resultados numéricos que indicam a validade de duas conjecturas.

A primeira conjectura é que os dois processos constituem o modo dominante, se não o único, pelo qual ocorre a formação de cadeias abertas de ilhas no interior da barreira de transporte. Entende-se aqui por cadeias abertas aquelas que se estendem ao longo de toda a barreira. As cadeias que mostramos nas figuras 4.1 e 4.3 são exemplos de cadeias abertas, ao contrário daquelas que surgem dentro de uma única ilha, contornando o seu ponto elíptico. E quando dizemos modo dominante, isso significa que todas as cadeias abertas nascem, para algum valor do parâmetro de pertubação, de acordo com um dos dois processos descritos anteriormente. Assim, tudo o que já se disse a respeito dos cenários par e ímpar caracterizam o modo como essas cadeias se originam e como elas evoluem.

A segunda conjectura estabelece uma relação entre a topologia da reta dos número 
reais e a topologia do espaço de fase na região interna da barreira. À medida em que se aumenta o valor do parâmetro de pertubação, a superfície $S_{\omega}$ se deforma continuamente. Essa deformação se caracteriza pela diminuição da largura da base - o que representa o avanço da região caótica em ambos os lados da barreira - e pela elevação da altura máxima de $S_{\omega}$. Quando essa altura máxima cruzar um nível que corresponde a um número irracional, o topo de $S_{\omega}$ está ocupado por uma curva shearless. Se o nível for um racional $m / n$, ocorre a formação de duas cadeias de ilhas com número de rotação também igual a $m / n$. Como vimos no capítulo $2, n$ é o número de ilhas de cada uma das cadeias. Este número indica o tipo de cenário de formação de órbitas periódicas. Em resumo, o que essa conjectura diz é que haverá tantas cadeias de ilhas quantos forem os racionais na faixa de números de rotação associada à região dentro da barreira.

Para ilustrar o que acabamos de discutir a respeito destas duas conjecturas, analisemos os resultados mostrados na figura 4.11 .

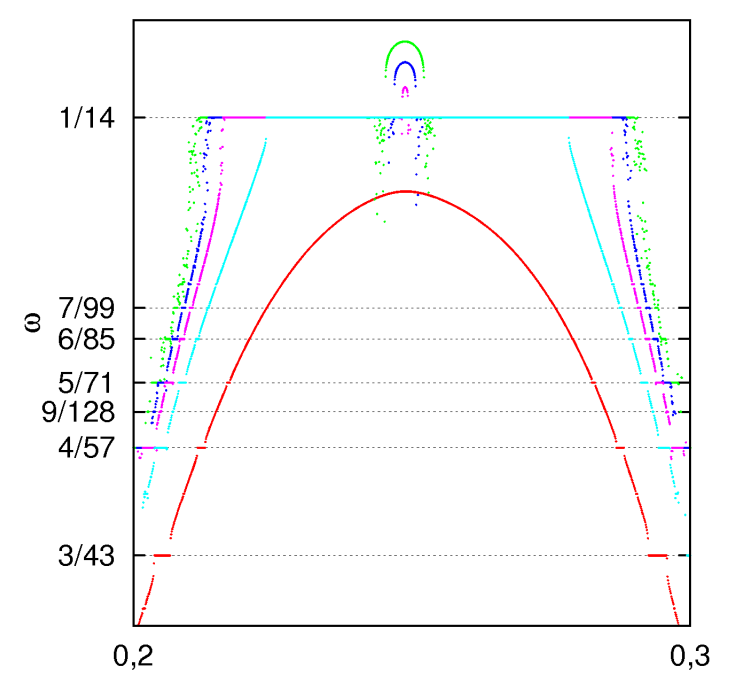

(a)

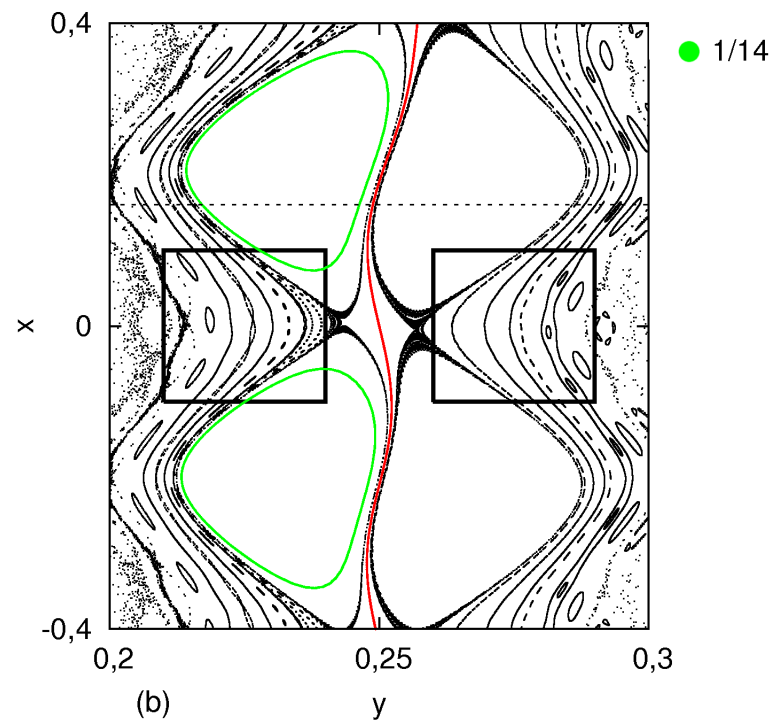

(b)

Figura 4.11: Nascimento da órbita 1/14, cujo período é par: (a) variação do perfil de $\omega$ com o aumento do parâmetro de controle; (b) cadeias de ilhas $1 / 14$ (em verde) para $a=0.4205$.

A figura 4.11(a) mostra perfis de números de rotação para valores crescentes do parâmetro de controle. A tabela 4.1 indica a sequência de valores adotada. Perfis de números de rotação, como já dissemos na seções 4.3 .1 e 4.3.2, dão-nos uma idéia de como $S_{\omega}$ se deforma durante a formação das órbitas periódicas. Na figura 4.11(a), identifica-se o 


\begin{tabular}{|c|c|c|}
\hline Gráfico & Parâmetro (a) & Cor \\
\hline Perfil 1 & 0.4165 & \\
\hline Perfil 2 & 0.4195 & \\
\hline Perfil 3 & 0.4205 & \\
\hline Perfil 4 & 0.4215 & \\
\hline Perfil 5 & 0.4225 & \\
\hline
\end{tabular}

Tabela 4.1: Valores do parâmetro de controle para os perfis mostrados na 4.11(a).

surgimento de um par de cadeias com número de rotação igual a 1/14. No apêndice, descreve-se o método utilizado para estimar os número de rotação associados a cadeias de ilhas.

O perfil 1 possui um ponto de máximo, cuja altura é inferior o valor $1 / 14$. Para o perfil 2, aparece o par de cadeias. As cadeias 1/14 crescem de tamanho e permanecem coladas para uma certa faixa de variação do parâmetro. Já no perfil 3, vê-se que essas cadeias se encontram separadas, pois se observam dois patamares e um ponto shearless entre eles. Os perfis 4 e 5 mostram o distanciamento cada vez maior entre as cadeias ao mesmo tempo em que cresce entre elas um perfil semelhante ao inicial (perfil 1). Também se observa a progressiva fragmentação das laterais, sinal do avanço da região caótica sobre a barreira.

As cadeias também podem ser vistas no mapa da figura 4.11(b), em que se usa o mesmo parâmetro do perfil 3. A trajetória em vermelho corresponde à curva shearless. É nela onde surgem as ilhas $1 / 14$. Os perfis de 1 a 5 foram construídos a partir de condições inicias sobre a linha tracejada $(x=0.16$ e $0.2 \leq y \leq 0.3)$.

Essa linha cruza não apenas a cadeia 1/14 como também muitas outras cadeias que se encontram ao lado dela. Isso é evidente quando retornamos à figura 4.11(a) e observamos pequenos patamares em todos os perfis. Os números de rotação desses patamares, todos racionais, também são mostrados no eixo $\omega$. Para um mesmo número de rotação, existem dois patamares em lados opostos do ponto shearless. Isso significa que cadeias com o mesmo número de rotação aparecem em lados opostos da curva shearless. É o que podemos verificar observando as ampliações das áreas retangulares da fig. 4.11(b). 
Elas são apresentadas nas figuras 4.12(a) e (b). Um grande número de cadeias pode ser
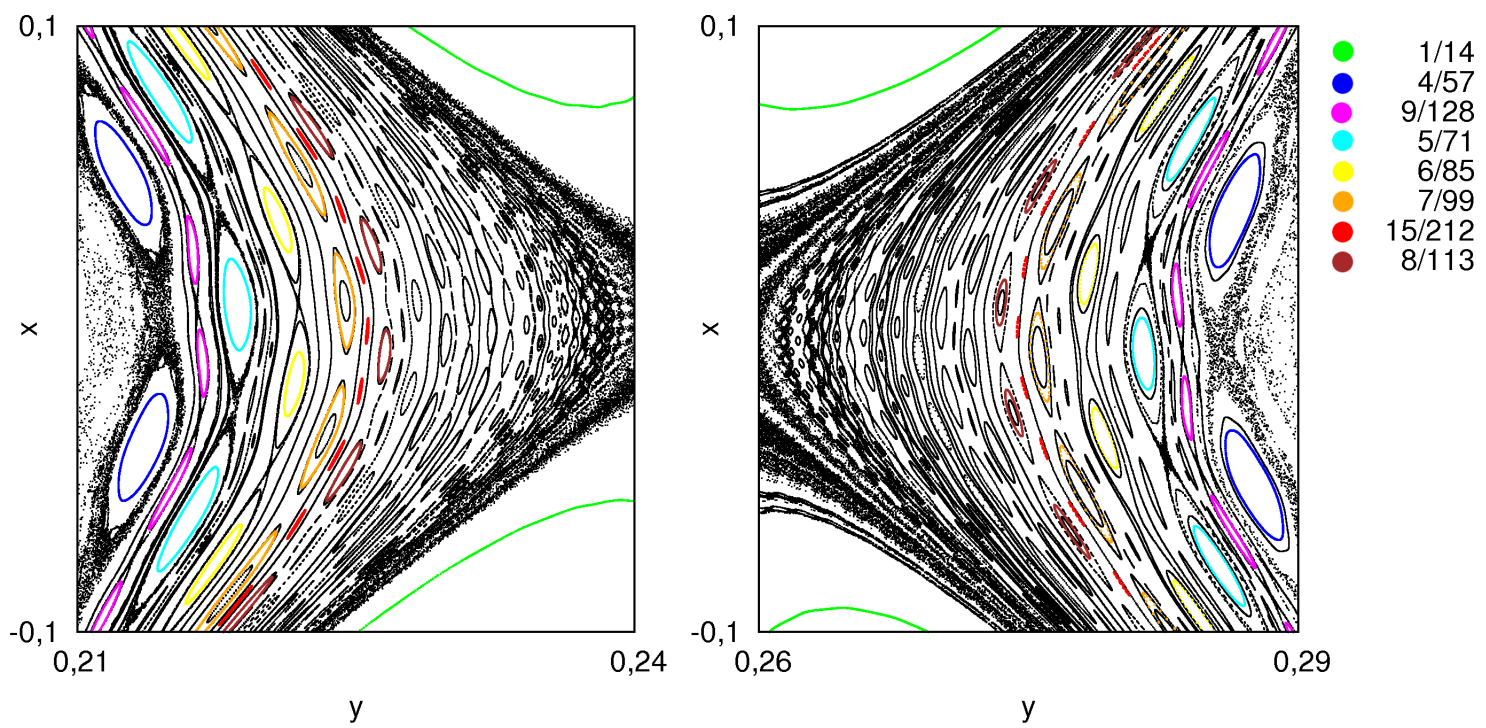

Figura 4.12: Ampliação das áreas retangulares da figura 4.11: pares de cadeias em lados opostos da curva shearless e com o mesmo número de rotação.

encontrado em 4.12(a), e os pares correspondentes a cada uma delas são vistos em 4.12(b). Entre essas cadeias, mostramos as que já foram indicadas pelos patamares dos perfis $1-5$. Vemos que esses patamares, nos perfis com maiores valores para o parâmetro de controle, estão mais afastados do eixo de simetria, ou seja, as cadeias estão mais afastadas da região mais interna da barreira, na qual se encontra a curva shearless.

O fato de essas cadeias aparecerem aos pares e de os experimentos mostrarem que elas sempre se deslocam para fora da barreira leva-nos a supor que, retrocendo o parâmetro, elas tenham todas se originado sobre uma curva shearless, reproduzindo os cenários par ou impar, de acordo com número de ilhas da cadeia. Essas observações sugerem, portanto, a validade da primeira conjectura.

Vamos ilustrar isso através de um caso particular: o par de cadeias 4/57. Destacamos esse par de cadeias nas figs.4.12(a) e (b) (ilhas em azul). Para o parâmetro usado, as ilhas se encontram na região caótica e, portanto, fora da barreira. Diminuido o parâmetro, elas se aproximam até que podemos identificá-las logo após o seu nascimento, mostrado na figura 4.13.A curva em vermelho corresponde à curva shearless, e as ilhas 4/57 encontramse bem próximas a ela. A configuração que as cadeias assumem é a mesma do cenário 
ímpar: pontos elípticos de uma cadeia alinhados com os pontos hiperbólicos da outra. É importante dizer a dificuldade observada de se localizar, no mapa, as cadeias logo após o seu nascimento: à medida em que elas se aproximam da curva shearless, as ilhas tendem a ficar cada vez mais "achatadas", de modo que a cadeia se parece cada vez mais com uma curva invariante. A dificuldade é ainda maior se a cadeia possui um número elevado de ilhas, pois, quanto maior esse número, menores elas são em tamanho.

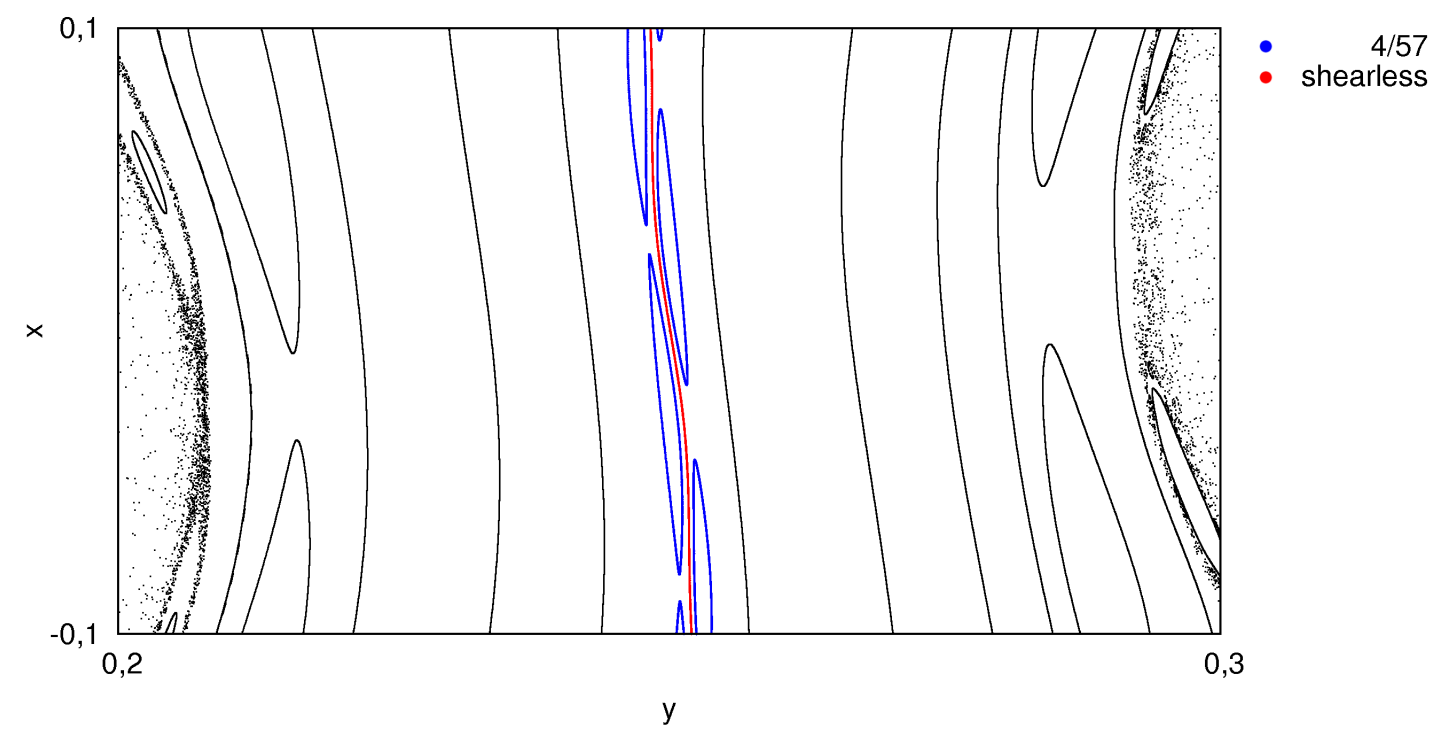

Figura 4.13: Nascimento da cadeia de ilhas 4/57 próximo à curva shearless. Parâmetro: $a=0.40943$.

Retornemos aos perfis da 4.11(a). Quando o ponto shearless estiver prestes a atingir um número racional, espera-se que a curva shearless ceda lugar a um órbita periódica. Supondo que a altura do ponto shearless varie de forma contínua com o parâmetro de controle, para cada número racional do eixo $\omega$ no intervalo de valores apresentados pelo perfil, é possível observar o nascimento de uma cadeia de ilhas. O conjunto dos números racionais é não enumerável. Não faz sentido, portanto, falar em "sequência" ou "sucessão" de cadeias quando se analisa seus números de rotação: para uma dada cadeia de ilhas, não existe a "cadeia anterior "ou a "próxima ", pois, entre dois racionais quaisquer, existem infinitos outros racionais. Essa é a idéia exposta na segunda conjectura, e a quantidade aparentemente infinita de cadeias nas ampliações 4.12(a)-(b) é um forte indício que corrobora essa conjectura.

As figuras 4.14, 4.15 e 4.16 são similares às anteriores. Para construir os perfis de 6 


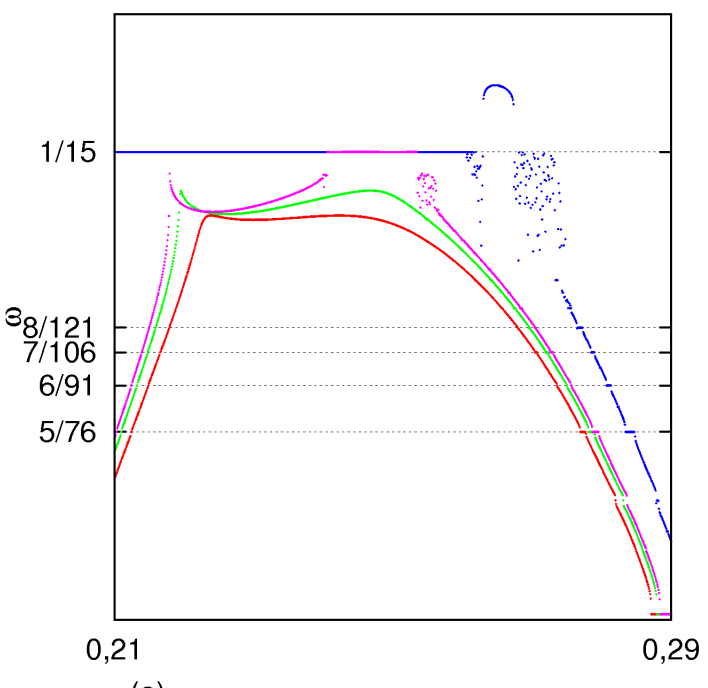

(a)

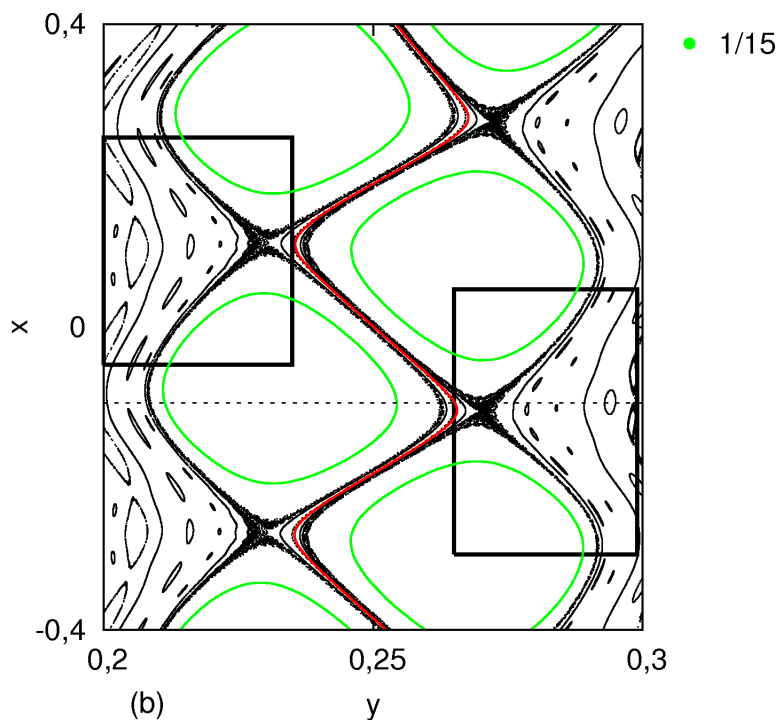

Figura 4.14: Nascimento de órbitas de período impar: (a) evolução do perfil de número de rotação; (b) cadeias de ilhas $1 / 15(a=0.3855)$.

a 9 na fig.4.14(a), usou-se a faixa de parâmetros da tabela 4.2. O modo como os perfis evoluem é característico do nascimento de órbitas de período ímpar, como já pudemos verficar na seção 4.3.2. O número de rotação da cadeia de ilhas que está nascendo é 1/15. Antes de atingir esse valor, supõe-se que o ponto shearless tenha cruzado não apenas os racionais indicados no eixo $\omega$ como também infinitos outros, gerando um número infinito de órbitas periódicas.

\begin{tabular}{|c|c|c|}
\hline Gráfico & Parâmetro (a) & Cor \\
\hline Perfil 6 & 0.3825 & \\
\hline Perfil 7 & 0.3830 & \\
\hline Perfil 8 & 0.38325 & \\
\hline Perfil 9 & 0.3855 & \\
\hline
\end{tabular}

Tabela 4.2: Valores do parâmetro de controle para os perfis mostrados na figura 4.14(a).

A cadeia $1 / 15$ pode ser vista no mapa da figura 4.14(b). O valor do parâmetro é o mesmo usado para o perfil 9. A curva shearless, em vermelho, também é mostrada, além de uma linha tracejada $(x=-0.1$ e $0.2 \leq y \leq 0.3)$ na qual se encontram as condições iniciais usadas para cálculo dos perfis. 
As áreas retangulares são ampliadas nas figs.4.15(a)-(b). Como no caso anterior, identificam-se pares de cadeias com o mesmo número de rotação em lados opostos da curva shearless. Os números de rotação das ilhas coloridas não seguem nenhuma sequência definida, e, entre uma cadeia e outra, é possível encontrar cadeias com ilhas menores.
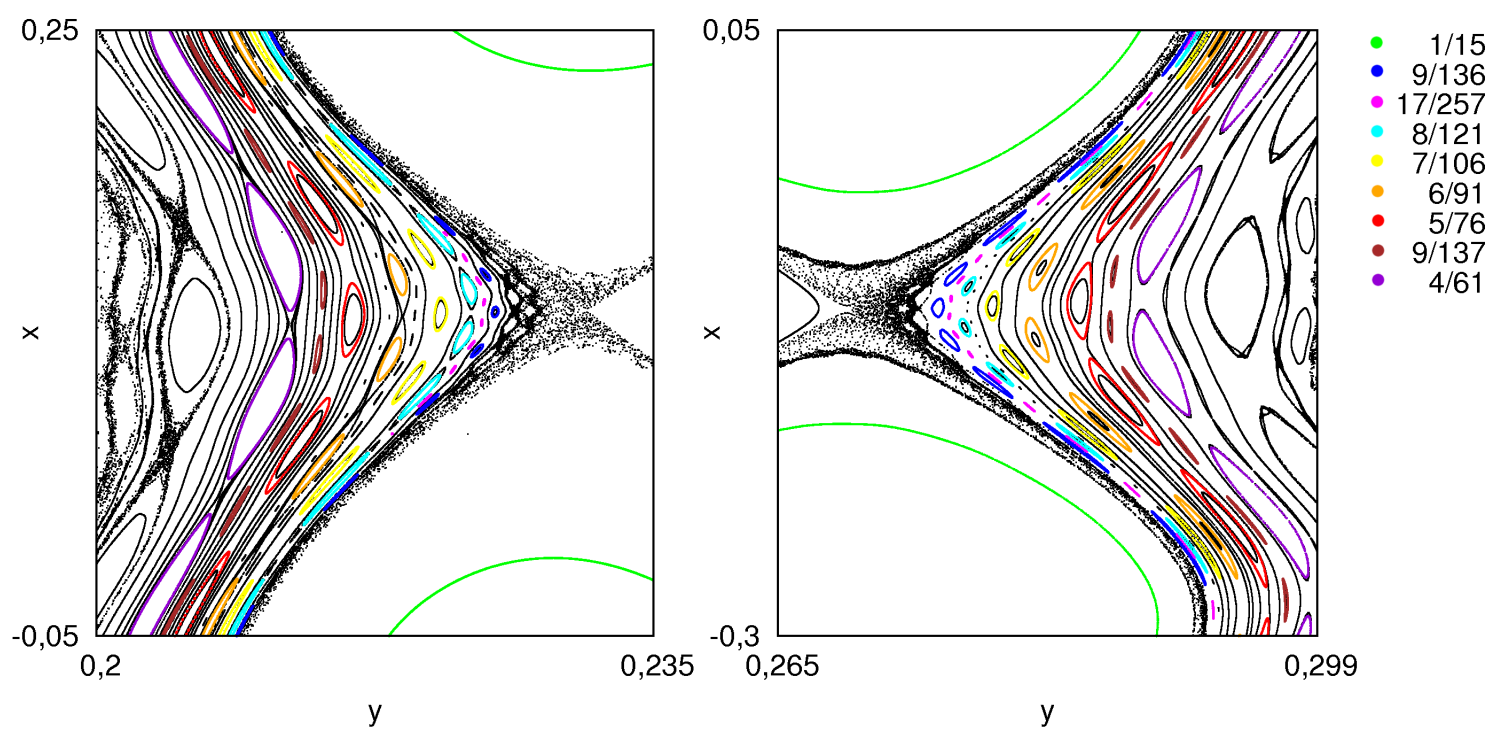

Figura 4.15: Ampliação sobre áreas retangulares da figura 4.14: pares de cadeias em lados opostos da curva shearless e com o mesmo número de rotação.

De modo análogo ao que fizemos anteriormente, mostra-se, na figura 4.16, o mapa logo após o nascimento do par de cadeias 5/76. O mesmo par é visto, para um maior valor para o parâmetro de controle, na figs. 4.15(a)-(b). Esse caso, para o qual existem 76 ilhas em cada cadeia, corresponde ao cenário de formação de órbitas de período par. Observemos que cada ponto elíptico está em frente a outro ponto elíptico da outra cadeia.

Utilizando a mesma sequência de parâmetros das figs.4.1(a)-(b), vejamos, agora, o nascimento do par de cadeias 1/16. É interessante notar que, ao contrário dos casos anteriores, não se observam patamares nos perfis da fig.4.17(a). Do mesmo modo, pelo menos na escala adotada, cadeias de ilha menores não são identificadas na região próxima ao par de cadeias 1/16, mostrado na fig. 4.17(b). Se estamos corretos quanto à segunda conjectura, a existência de infinitos racionais próximos ao número 1/16 implicaria também em infinitos pares de cadeias. Mas onde estão essas ilhas menores? À primeira vista, poderia ser esse caso um contra-exemplo das hipóteses que apresentamos até agora. 


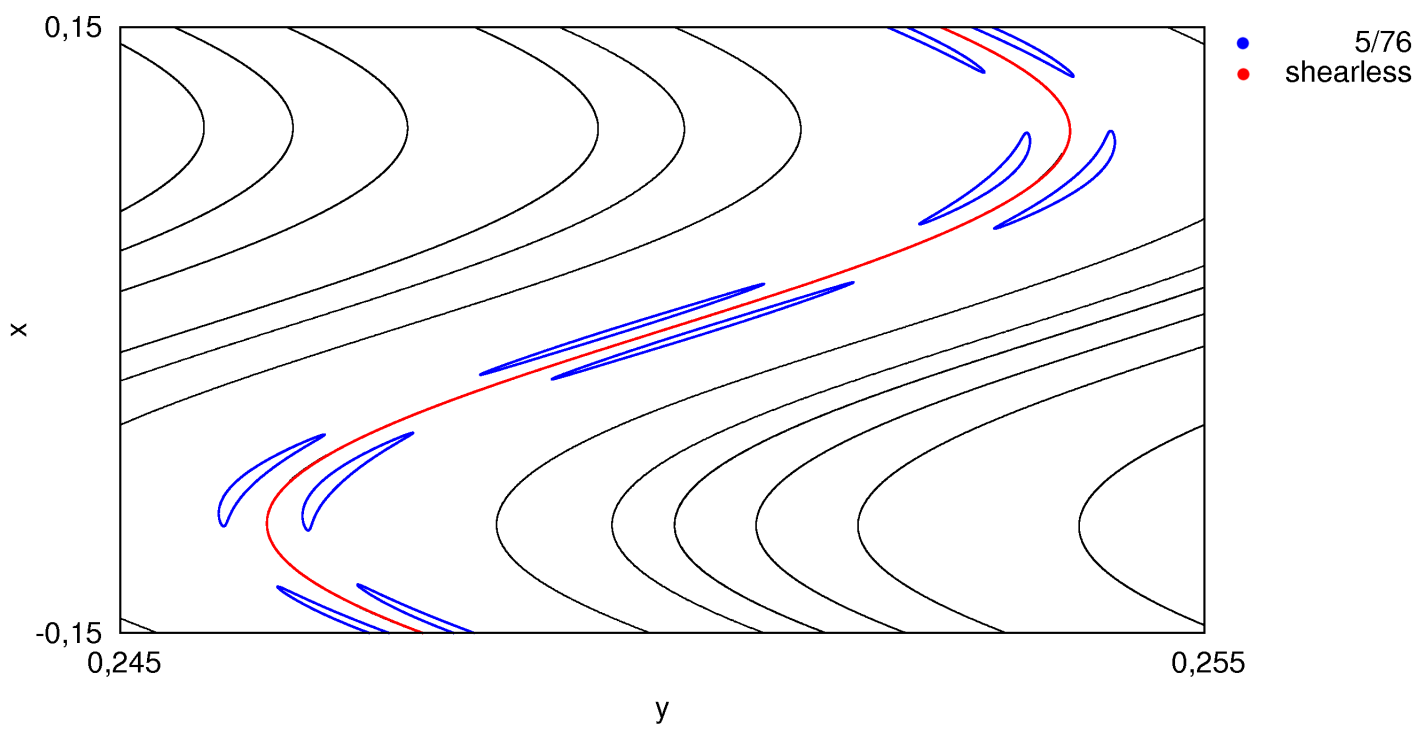

Figura 4.16: Nascimento da cadeia de ilhas $5 / 76$ próximo à curva shearless. $a=0.376622$.

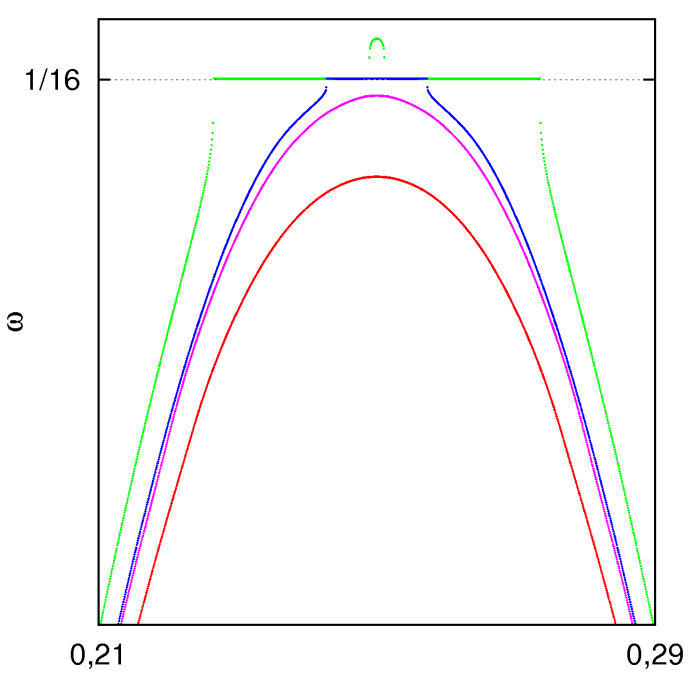

(a)

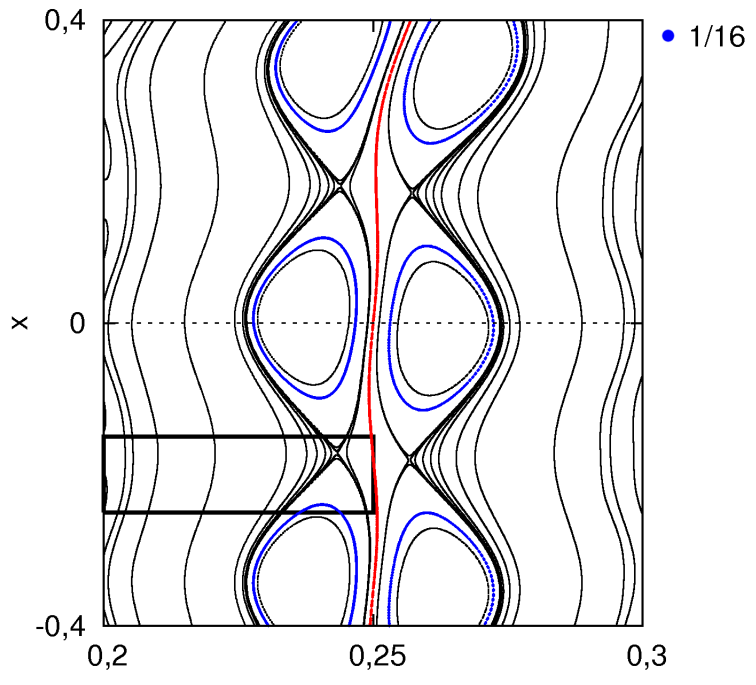

(b)

Figura 4.17: Nascimento da cadeia de ilhas $1 / 16$. Na escala apresentada, não se observam cadeias de ilhas menores.

Ao mostrarmos o nascimento das cadeias 4/57 e 5/76 (figs.4.13 e 4.16), mencionamos a dificuldade de se localizá-las no espaço de fase em razão da forma "achatada "das cadeias, que as fazem parecidas com uma curva invariante. É possível que este efeito esteja presente na região próxima ao par de cadeias $1 / 16$, dificultando a visualização de outras cadeias.

Ampliando a área retangular em 4.17(b) e apresentando-a na figura 4.18, vemos, além da cadeia principal 1/16, parte de uma cadeia cujas ilhas, destacadas em verde, mostram- 


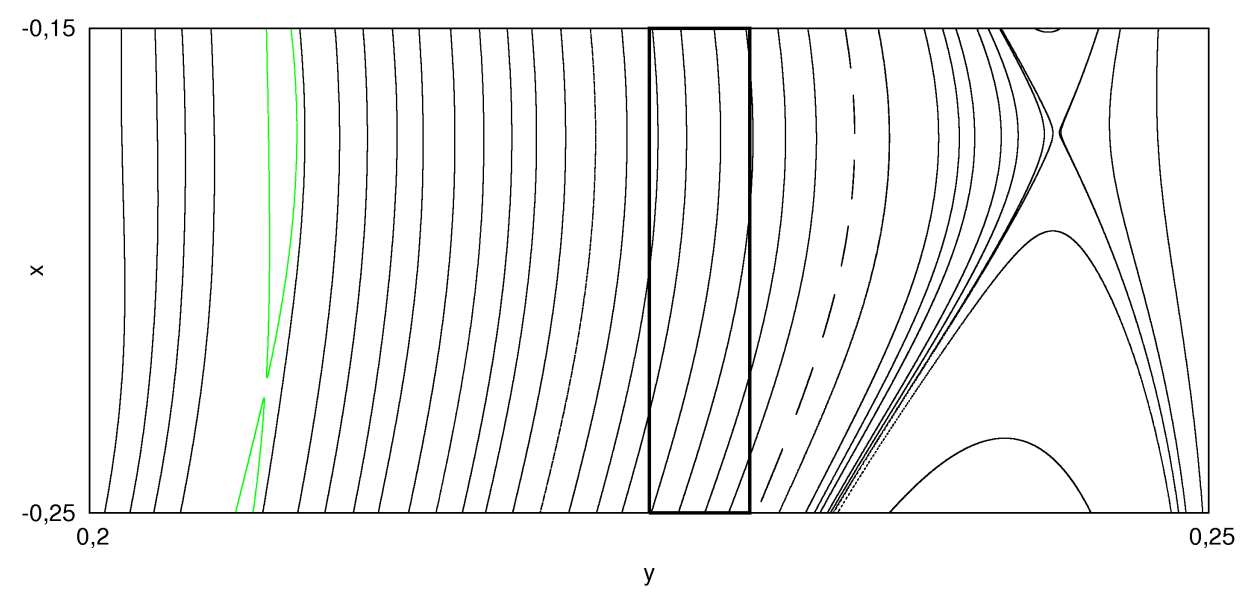

Figura 4.18: Ampliação da área retangular da figura 4.17

se bastante "achatadas". Aproximando-se da cadeia principal, observa-se uma trajetória descontínua, semelhante a uma linha tracejada. Pode-se pensar que esta trajetória seja uma curva invariante com um número de pontos insuficiente para preenchê-la completamente. No entanto, aumentando-se bastante o número de pontos, a trajetória permanece inalterada. Trata-se, portanto, de uma cadeia de ilhas. Elas estão tão "achatadas" que não as percebemos.

Embora tenhamos identificado mais duas cadeias na figura 4.18, o espaço de fase parece estar dominado por curvas invariantes, o que ainda nos deixa em dúvida quanto à validade da segunda conjectura. Contudo, na área retangular da mesma figura, façamos mais uma ampliação, cujo resultado pode ser visto na figura 4.19. Depois de aumentarmos significativamente a escala horizontal, como se a figura se "dilatasse" na direção do eixo $y$, torna-se possível identificar um número maior de cadeias, ainda que as ilhas se mostrem bastante "achatadas". Se repetirmos as operações de ampliação de áreas localizadas seguidas por dilatações horizontais, esperamos que mais e mais cadeias irão aparecer, o que corrobora a segunda conjectura. Embora os resultados apresentados não constituam provas rigorosas, tornam-se mais evidentes os indícios de que existe uma relação íntima entre a topologia da reta, caracterizada pelo conjunto dos números reais, e a topologia do espaço de fase dentro da barreira de transporte. 


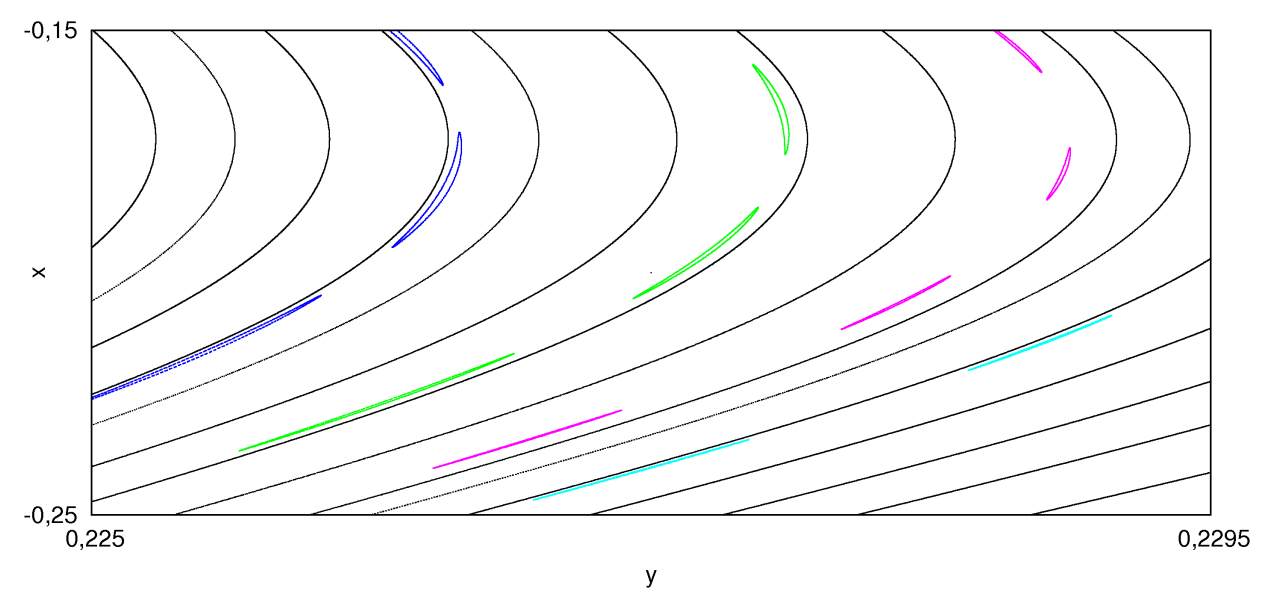

Figura 4.19: Ampliação da área retangular da figura 4.18

\subsection{Conclusão}

Este capítulo procurou descrever aspectos da "fenomenologia" numérica da barreira de transporte no mapa modelo: foram apresentados os cenários par e ímpar, que mostram como o espaço de fase se modifica dentro da barreira quando se varia um de seus parâmetros.

Os cenários, também observados em outros mapas não-twist, mostram o surgimento de cadeias de ilhas (nascimento de órbitas periódicas), o crescimento da área ocupada por essas cadeias e sua expulsão para fora da barreira, fragmentando-se em ilhas isoladas nas regiões caóticas.

Outra importante característica destes cenários é a relação que mantêm com os números de rotação $(\omega)$. Quando introduzimos a idéia de superfície de números de rotação $\left(S_{\omega}\right)$, vimos que os "topos" ou "vales" suaves em $S_{\omega}$ estão relacionadas às curvas invariantes chamadas de "shearless". As cadeias de ilhas surgem sobre curvas "shearless" em que $\omega$ possui valores máximos (topos de $S_{\omega}$ ).

Os resultados da última seção levaram à apresentação de duas conjecturas: a primeira é que todas as cadeias de ilhas surgem sempre de acordo com um dos dois cenários; a segunda afirma que, para cada racional $p / q$ do intervalo de números de rotação associado à região da barreira, existe um par de órbitas periódicas para os quais $\omega=p / q$. 


\section{Capítulo 5}

\section{Conclusão}

Como apresentado na introdução desta dissertação, o objetivo do trabalho é estudar barreiras de transporte previstas por um modelo Hamiltoniano com ondas de deriva em Tokamaks. A Hamiltoniana desse modelo depende do potencial elétrico na borda do plasma, que é formada por dois termos: um termo de equilíbrio, função apenas da coordenada radial, e outro que traduz os efeitos das ondas de deriva, função da coordenada poloidal e do tempo.

A estrutura da Hamiltoniana tornou possível reescrever as equações de movimento na forma de um mapa simplético bidimensional e não linear. Conceitos e ferramentas da teoria de mapas simpléticos puderam, assim, ser usados na obtenção e análise de resultados numéricos.

A Hamiltoniana contém o perfil do campo elétrico radial, que resulta de instabilidades espontâneas na borda do plasma ou da aplicação de técnicas experimentais de controle. Assumimos três perfis diferentes, e os mapas simpléticos obtidos foram o mapa padrão, o mapa padrão não-twist e o mapa modelo. Este último foi proposto durante nosso trabalho de pesquisa.

Verificamos que a presença de pontos sem "shear" nos perfis implica na violação da condição "twist". Entre os mapas obtidos, o único em que isso não ocorre é o mapa padrão. Analisamos órbitas numericamente para os três mapas e verificamos a relação existente entre os mapas não-twist (o mapa modelo e o mapa padrão não-twist) e a formação de barreiras de transporte robustas. Esta relação foi indicada por trabalhos anteriores, 
conforme discutimos nos capítulo 1.

Outro aspecto, já evidenciado em outros mapas não-twist, e que confirmamos aqui para o mapa modelo, são processos de bifurcação que ocorrem como resultado da variação de parâmetros de controle. Os processos de bifurcação, localizados dentro da barreira de transporte, estão associados ao nascimento de pares de órbitas periódicas, reconexão de separatrizes e formação de "meanders".

Estes processos foram estudados, no capítulo 4, com o uso do mapa modelo. Inicialmente, mostramos as alterações geométricas das órbitas dentro da barreira em função da variação de um dos parâmetros do mapa, o que nos levou à caracterização dos cenários par e ímpar. Ambos os cenários foram analisados através dos numeros de rotação. As variações destes números na região interna à barreira, provocada por alterações do parâmetro de controle, levaram-nos a elaborar duas conjecturas.

Na primeira conjectura, afirmamos que as cadeias de ilhas surgem dentro da barreira segundo apenas um dos dois cénários. O que determina qual cenário vai ocorrer é o valor racional $p / q$ do número de rotação: o cenário é par para valores pares de $q$ e ímpar para os valores ímpares.

A segunda conjectura está diretamente ligada à primeira e afirma que, para cada racional no intervalo de números de rotação apresentado pela barreira, um par de cadeias de ilhas será observado. Quando o número é irracional, teremos uma curva invariante. Esta propriedade é similar às características apresentadas pela "escada do diabo" no mapa do círculo [41]. Esta possível relação poderá ser estudada futuramente, analisando-se como o número de rotação, em determinado ponto próximo à curva "shearless", varia em função do parâmetro de controle.

Cenários de bifurcação mais complexos do que os apresentados aqui foram investigados por [42] para uma versão modificada do mapa padrão não-twist. Não observamos tais cenários no mapa modelo, mas é possivel que eles estejam ocorrendo em escalas menores em relação às analisadas neste trabalho, o que será investigado posteriormente.

Outra sugestão a respeito do que pode ser tratado futuramente é o estudo sobre a quebra da barreira no mapa modelo, aplicando os mesmos métodos usados por [38] e [32] para identificar parâmetros críticos que determinam a destruição de curvas "shearless" no 
mapa padrão não-twist. Entre estes métodos, pode-se citar o critério de Greene e a teoria de grupos de renormalização.

Esperamos, com este trabalho, ter apresentado contribuições sobre a formação e propriedades de barreiras de transporte em plasmas confinados magneticamente, nossa principal motivação durante o trabalho de pesquisa. 


\section{Referências Bibliográficas}

[1] A. H. Boozer. Physics of magnetically confined plasmas. Rev. Mod. Phys., 76(4), 2005 .

[2] P. H. Diamond, S.-I. Itoh, and K. Itoh. Modern Plasma Physics Vol. I - Physical Kinetics of Tubulent Plasmas. Cambridge University Press, first edition, 2010.

[3] J. Wesson. Tokamaks. Oxford University Press, 1987.

[4] Iter physics basis. Nuclear Fusion, 39(12), 1999.

[5] S.-I Itoh, K. Itoh, and A. Yoshizawa. Plasma and Fluid Turbulence: theory and modelling. Institute of Physics(IoP), third edition, 1999.

[6] C. Hidalgo. On the nature of transport in fusion plasmas. Astrophysics and Space Science, 292, 2004.

[7] X. Garbet, T. Tala, and JET EFDA contributors. Physics of internal transport barriers. C. R. Physique, (7), 2006.

[8] R. C. Wolf. Internal transport barriers in tokamak plasmas. Plasma Physics and Controlled Fusion, 45(1), 2003.

[9] Dale Meade. 50 years of fusion research. Nuclear Fusion, 50(1), 2010.

[10] F. A. Marcus, I. L. Caldas, Z. O. Guimarães-Filho, P. J. Morrison, W. Horton, Yu. K. Kuznetsov, and I. C. Nascimento. Reduction of chaotic particle transport driven by drift waves in sheared flows. Physics of Plasmas, 15, 2008.

[11] W. Horton. Drift waves and transport. Rev. Mod. Phys., 71(3):735-778, 1999. 
[12] C. G. L. Martins, R. Egydio de Carvalho, I. L. Caldas, and M. Roberto. Plasma confinement in tokamaks with robust torus. Physica A: Statistical Mechanics and its Applications, 390(5), 2011.

[13] J. S. E. Portela, I. L. Caldas, R. L. Viana, and P. J. Morrison. Diffusive transport through a nontwist barrier in tokamaks. International Journal of Bifurcation and Chaos, 17, 2007.

[14] R. Balescu. Hamiltonian nontwist map for magnetic field lines with locally reversed shear in toroidal geometry. Phys. Rev. E, 58(3), 1998.

[15] Wendell Horton, Hyoung-Bin Park, Jae-Min Kwon, D. Strozzi, P. J. Morrison, and Duk-In Choi. Drift wave test particle transport in reversed shear profile. Physics of Plasmas, 5(11), 1998.

[16] Lorenzo Nasi and Marie-Christine Firpo. Enhanced confinement with increased extent of the low magnetic shear region in tokamak plasmas. Plasma Physics and Controlled Fusion, 51(4), 2009.

[17] G. Corso and F. B. Rizzato. Manifold reconnection in chaotic regimes. Phys. Rev. E, 58(6), 1998.

[18] D. Del-Castillo-Negrete and P.J. Morrison. Chaotic transport by rossby waves in shear flow. Phys. Fluids A, 5, 1993.

[19] I.L. Caldas, R.L. Viana, J.D. Szezech Jr., J.S.E. Portela, J. Fonseca, M. Roberto, and C.G.L. Martins andE.J. da Silva. Nontwist symplectic maps in tokamaks. Communications in Nonlinear Science and Numerical Simulation, 2011.

[20] R. Egydio de Carvalho and A. M. Ozorio de Almeida. Integrable approximation to the overlap of resonances. Physics Letters A, 162(6), 1992.

[21] W. Horton. Onset of stochasticity and the diffusion approximation in drift waves. Plasma Phys. Control. Fusion, 27(9), 1985. 
[22] L. D. Landau and E.M. Lifshitz. Mechanics: Volume 1 (Course of Theoretical Physics). Pergamon Press, third edition, 1976.

[23] E. R. de Lascio. Trasnporte caótico em plasmas. Master's thesis, Instituto de Física, Universidade de São Paulo, Brasil, 2008.

[24] J. Yorke, K. Alligood, and T. Sauer. Chaos: An Introduction to Dynamical Systems. Springer-Verlag, third edition, 2000.

[25] J.D. Meiss. Symplectic maps, variational principles, and transport. Rev. Mod. Phys, 64, 1992.

[26] E. Ott. Chaos in Dynamical Systems. Cambridge University Press, third edition, 1993.

[27] L. Reichl. The Transition to Chaos: Conservative Classical Systems and Quantum Manifestations. Cambridge University Press, second edition, 1993.

[28] G. Tigan. On the scenario of reconnection in non-twist cubic maps. Chaos, Solitons and Fractals, 30, 2006.

[29] C. Simó. Invariant curves of analytic perturbed nontwist area preserving. 180, 3, 1998.

[30] E. Petrisor. Nontwist area preserving maps with reversing symmetry group. International Journal of Bifurcation and Chaos, 11, 2002.

[31] A. Wurm, A. Apte, K. Fuchss, and P. J. Morrison. Meanders and reconnectioncollision sequences in the standard nontwist map. Chaos: An Interdisciplinary Journal of Nonlinear Science, 15(2), 2005.

[32] K. Fuchss, A. Wurm, A. Apte, and P. J. Morrison. Breakup of shearless meanders and "outer" tori in the standard nontwist map. Chaos: An Interdisciplinary Journal of Nonlinear Science, 16(3), 2006. 
[33] A. Apte. Numerical Studies of the Standard Nontwist Map and a Renormalization Group Framework for Breakup of Invariant Tori. PhD thesis, The University of Texas at Austin, 2004.

[34] R. R. Weynants. Edge radial electric fields and their importance for confinement. Transactions of Fusion Technology, 29, 1996.

[35] P. J. Morrison. Magnetic field lines, hamiltonian dynamics, and nontwist systems. Physics of Plasmas, 7(6), 2000.

[36] D. Del-Castillo-Negrete. Ph. D. thesis. PhD thesis, The University of Texas at Austin, Austin,Texas, 1995.

[37] Jr. J. D. Szezech, I. L. Caldas, S. R. Lopes, R. L. Viana, and P. J. Morrison. Transport properties in nontwist area-preserving maps. Chaos: An Interdisciplinary Journal of Nonlinear Science, 19(4), 2009.

[38] D. Del-Castillo-Negrete, J.M. Greene, and P.J. Morrison. Area preserving nontwist maps: periodic orbits and transition to chaos. Physica D, 91, 1996.

[39] A. Apte, A. Wurm, and P. J. Morrison. On reconnection phenomena in the standard nontwist map. Brasilian Journal of Physics, 34, 2004.

[40] J. E. Howard and Jeffreys Humpherys. Nonmonotonic twist maps. Physica D, 80, 1995.

[41] P. Bak, H. Jensen, and T. Bohr. Complete devil's staircase, fractal dimension, and universality of mode- locking structure in the circle map. Phys. Rev. Lett., 50(21), 1983.

[42] C. G. L. Martins, R. Egydio de Carvalho, I. L. Caldas, and M. Roberto. Labyrinthic standard non-twist map. Journal of Physics A: Mathematical and Theoretical, 44(4), 2011. 